\title{
Medicinal Plants from North and Central America and the Caribbean Considered Toxic for Humans: The Other Side of the Coin
}

\author{
Angel Josabad Alonso-Castro, ${ }^{1}$ Fabiola Domínguez, ${ }^{2}$ \\ Alan Joel Ruiz-Padilla, ${ }^{1}$ Nimsi Campos-Xolalpa, ${ }^{3}$ Juan Ramón Zapata-Morales, ${ }^{1}$ \\ Candy Carranza-Alvarez, ${ }^{4}$ and Juan Jose Maldonado-Miranda ${ }^{4}$ \\ ${ }^{1}$ Departamento de Farmacia, División de Ciencias Naturales y Exactas, Universidad de Guanajuato, Guanajuato, GTO, Mexico
${ }^{2}$ Centro de Investigación Biomédica de Oriente, Instituto Mexicano del Seguro Social, Metepec, PUE, Mexico
${ }^{3}$ Departamento de Sistemas Biológicos, Universidad Autónoma Metropolitana, Unidad Xochimilco, Mexico City, Mexico
${ }^{4}$ Unidad Académica Multidisciplinaria de la Zona Huasteca, Universidad Autónoma de San Luis Potosí, Ciudad Valles, SLP, Mexico
}

Correspondence should be addressed to Angel Josabad Alonso-Castro; angeljosabad@hotmail.com

Received 14 August 2017; Revised 4 October 2017; Accepted 10 October 2017; Published 2 November 2017

Academic Editor: Karin Kraft

Copyright (C) 2017 Angel Josabad Alonso-Castro et al. This is an open access article distributed under the Creative Commons Attribution License, which permits unrestricted use, distribution, and reproduction in any medium, provided the original work is properly cited.

\begin{abstract}
The consumption of medicinal plants has notably increased over the past two decades. People consider herbal products as safe because of their natural origin, without taking into consideration whether these plants contain a toxic principle. This represents a serious health problem. A bibliographic search was carried out using published scientific material on native plants from Mexico, Central America, and the Caribbean, which describe the ethnobotanical and toxicological information of medicinal plants empirically considered to be toxic. A total of 216 medicinal plants belonging to 77 families have been reported as toxic. Of these plants, 76 had been studied, and 140 plants lacked studies regarding their toxicological effects. The toxicity of 16 plants species has been reported in clinical cases, particularly in children. From these plants, deaths have been reported with the consumption of Chenopodium ambrosioides, Argemone mexicana, and Thevetia peruviana. In most of the cases, the principle of the plant responsible for the toxicity is unknown. There is limited information about the toxicity of medicinal plants used in Mexico, Central America, and the Caribbean. More toxicological studies are necessary to contribute information about the safe use of the medicinal plants cited in this review.
\end{abstract}

\section{Introduction}

The use of herbal medicine has increased around the world due to its presumptive efficiency, availability, and general acceptance. Approximately $80 \%$ of the general population, especially in developing countries, uses medicinal herbs for primary health care $[1,2]$. Worldwide, the interest in medicinal plants by patients has increased over the past two decades. The global market for medicinal plants and plantderived drugs in 2015 was estimated at 25.6 billion dollars and is expected to rise to 35.4 billion dollars in 2020 [3]. This clearly indicates that the consumption of medicinal plants is a current topic of interest. Despite the high consumption of medicinal plants and related products, their toxicity remains to be evaluated. In addition, many medicinal plants require scientific evidence for their medicinal use, particularly those that are sold as food supplements.

Some medicinal plants might trigger undesirable side effects for human health because of (a) pharmacodynamic interaction with prescribed drugs, (b) intrinsic effects, (c) pharmacokinetic interaction with prescribed drugs, and (d) the presence of contaminants and/or pathogenic microorganisms. Other factors that impact the toxicity of medicinal plants in humans include the age of the patient, nutritional status, and the presence of chronic diseases. The concentration of toxic metabolites in plants is determined by the season 
of collection, nutrients in the soil, and growth stage, among others [4].

The main reasons for focusing this review on medicinal flora with supposed toxicological effects from Mexico, Central America, and the Caribbean are as follows: (a) the ancient importance of traditional medicine in this region, (b) their great biodiversity, and (c) the current use of herbal products. This review will be useful for physicians, toxicologists, pharmacologists, and general audiences. We have tried to describe in detail some toxic symptoms reported with the consumption of the medicinal plants covered in this review.

\section{Methodology}

A bibliographic search was conducted from July 2016 to May 2017 of published scientific material on native plants from Mexico, Central America, and the Caribbean that describes the ethnomedical and toxicological information for medicinal plants reputed to be toxic for humans. The following keywords were searched in different scientific databases: plant extract, toxicity, Mexico, and Central America. Additional data were acquired from undergraduate and postgraduate theses, as well as published and electronic books. The admittance criteria for the selection of scientific information in this review were as follows: (i) plants native to North and Central America and the Caribbean, (ii) plants used for medicinal purposes with or without toxicological studies, (iii) plants with experimental reports on their in vitro and/or in vivo toxicity, (iv) plants thought to be toxic for humans, (v) studies where the concentrations were presented as weight/volume relationship in international units $(\mathrm{mg} / \mathrm{ml}$, $\mu \mathrm{g} / \mathrm{ml}$ ), (vi) studies where the doses were presented as weight/weight relationship in international units $(\mathrm{mg} / \mathrm{kg}$, $\mathrm{g} / \mathrm{kg}$ ), and (vii) plants with information obtained from a clear source. Scientific studies reporting the combination of plant extracts were excluded. Medicinal plants considered toxic were classified into two categories: (1) plants with toxicological evidence reported in a scientific source and (2) plants without toxicological evidence. All plant names and their distributions were confirmed at the Missouri botanical garden [73]. Many of the medicinal plants cited in this review have no common name in English. Therefore, the common names were given in Spanish (Table 1).

\section{Medicinal Plants Considered to Be Toxic for Humans}

A total of 216 medicinal plants belonging to 77 families reported as toxic were recorded. Of these plants, 76 had been studied, and 140 plants lacked studies regarding their toxicological effects (Table 1). Aristolochia (6 plant species), Euphorbia (6 plant species), Solanum (5 plant species), and Asclepias (5 plant species) are the plant genera most often reported to induce toxicity (Table 1). Chemotaxonomic studies should be performed to identify the toxic principle in these genera. The parts of the plants considered toxic are listed in the following order: aerial parts including branches, leaves and flowers (22\%), whole plant (22\%), leaves exclusively
(15\%), seeds (14\%), roots (8\%), fruits ( $8 \%)$, bark (4\%), latex (3\%), and other plant parts.

The signs and symptoms of toxicity induced by medicinal plants are reported in Table 1 . The main toxic effects occur in the following order: nausea and vomiting (20\%), dermatitis (14\%), gastritis (9\%), abdominal pain (9\%), abortifacient $(8 \%)$, skin burns $(8 \%)$, hepatotoxicity $(7 \%)$, severe diarrhea (6\%), cardiotoxicity (5\%), nephrotoxicity (2\%), numbness (2\%), dizziness (2\%), and hallucinations (2\%), among others.

3.1. Dosages. In most of the cases, the dose for the induction of toxic effects by medicinal plants is not indicated. Usually, consumers of medicinal plants believe that increasing the consumption of these products will increase the efficacy of the treatment. In these cases, the daily dosage is exceeded, which triggers toxicity. For instance, the roots of Ipomoea purga, a purgative agent, are used at a dose of $2 \mathrm{~g} / \mathrm{L} /$ day. Administration of higher doses induces vomiting and abdominal pain [15]. Fresh leaves of Prunus serotina, used for the treatment of cough, or Zanthoxylum fagara, an anxiolytic agent, each must be consumed in a maximum quantity of five leaves in $250 \mathrm{ml}$ of water per day. Higher doses produce spasms and nausea [26]. Approximately $5 \mathrm{~mL}$ of an infusion of Picrasma excelsa $(10 \mathrm{~g} / \mathrm{L})$ should be administered three times per day. Higher doses induce hypotension. This infusion should not be prepared with ethanol and orally administered. If a person consumes the hydroalcoholic infusion, the consequences could be lethal [35]. The maximum consumption of Manilkara zapota seeds should be 10 seeds per day. A higher consumption of these seeds might induce vomiting and gastroenteritis [26]. On the other hand, SosaGómez [35] recommends the preparation of an infusion using approximately $1-3 \mathrm{~g}$ Argemone mexicana leaves in $1 \mathrm{~L}$ of water. This infusion should be taken 3 times per day. A higher dose might induce immobilization.

Studies analyzing the range of doses considered safe for human consumption remain to be performed. The use of natural products needs scientific evidence to corroborate the medicinal uses attributed to different plant species. Many medicinal plants sold as "food supplements" lack warnings if the suggested dosage is exceeded.

3.2. Toxic Principles. In some cases, the toxic principle is known. For instance, it is reported that cefalatin, the main toxic compound in Cephalanthus occidentalis bark, induces vomiting, anemia, and seizures, among other toxic effects. Similarly, hederagenin is the main toxic compound in Clematis dioica, which is a caustic substance [4]. Monocrotaline is the compound responsible for the toxic effects in Crotalaria sagittalis. Cianhidric acid, one of the most toxic compounds in plants, is found in Crescentia cujete fruit, Phaseolus lunatus whole plant, and Prunus serotina leaves and seeds [4]. In Phaseolus lunatus, the concentration of cianhidric acid ranges $6.8-533 \mathrm{mg} / \mathrm{kg} \mathrm{dw}[74,75]$. There is limited information on the major toxic compounds cited in this review. Therefore, the identification of toxic principles in medicinal plants is necessary. 
TABLE 1: Ethnobotanical information of medicinal plants from Mexico and Central America considered as toxic.

\begin{tabular}{|c|c|c|c|c|c|}
\hline Family & Scientific name & $\begin{array}{l}\text { Common name in } \\
\text { Spanish }\end{array}$ & Medicinal use & $\begin{array}{l}\text { Signs of toxicity } \\
\text { [plant part] }\end{array}$ & Reference \\
\hline \multirow[b]{2}{*}{ Amaranthaceae } & Amaranthus spinosus L. ${ }^{* *}$ & Quelite de Puerco & $\begin{array}{l}\text { Rheumatism, } \\
\text { diuretic, wound } \\
\text { healing }\end{array}$ & $\begin{array}{l}\text { Nephrotoxicity } \\
\text { [whole plant] }\end{array}$ & {$[5]$} \\
\hline & $\begin{array}{l}\text { Chenopodium ambrosioides } \\
\text { L. }^{* *}\end{array}$ & Epazote & Vermifuge, vomit & $\begin{array}{l}\text { Nephrotoxicity } \\
\text { abortifacient, } \\
\text { hepatotoxicity } \\
\text { [whole plant] }\end{array}$ & {$[6]$} \\
\hline Amaryllidaceae & $\begin{array}{l}\text { Allium glandulosum Link \& } \\
\text { Otto }\end{array}$ & Cebolla de monte & $\begin{array}{l}\text { Cough, flu, } \\
\text { tuberculosis }\end{array}$ & $\begin{array}{l}\text { Numbness, nausea, } \\
\text { and vomiting } \\
\text { [bulb] }\end{array}$ & {$[7]$} \\
\hline \multirow[t]{2}{*}{ Anacardiaceae } & Metopium brownei (Jacq.) Urb. & Chechém negro & $\begin{array}{c}\text { Antiviral, } \\
\text { Rheumatism }\end{array}$ & $\begin{array}{l}\text { Skin burns [latex } \\
\text { from leaves] }\end{array}$ & {$[8]$} \\
\hline & $\begin{array}{c}\text { Toxicodendron radicans }(\mathrm{L} .) \\
\text { Kuntze }\end{array}$ & Hiedra venenosa & $\begin{array}{l}\text { Headache, } \\
\text { rheumatism }\end{array}$ & Dermatitis [latex] & [9] \\
\hline Annonaceae & Annona cherimola Mill.** & Chirimoya & $\begin{array}{l}\text { Diarrhea, } \\
\text { dysentery }\end{array}$ & $\begin{array}{c}\text { Abortifacient } \\
\text { [aerial parts, fruits] }\end{array}$ & {$[10]$} \\
\hline \multirow[t]{6}{*}{ Apiaceae } & Conium maculatum L. $^{* *}$ & Cicuta & Body pain & $\begin{array}{c}\text { Hypertension and } \\
\text { sweating [whole } \\
\text { plant] }\end{array}$ & {$[11]$} \\
\hline & Asclepias curassavica L. & Rompemuelas & $\begin{array}{c}\text { Vermifuge, cancer, } \\
\text { wound healing, } \\
\text { diuretic }\end{array}$ & $\begin{array}{c}\text { Nausea and } \\
\text { vomiting, muscle } \\
\text { paralysis [whole } \\
\text { plant] }\end{array}$ & [12] \\
\hline & Asclepias linaria Cav. & Algodoncillo & $\begin{array}{c}\text { Cough, fever, } \\
\text { purgative, diuretic }\end{array}$ & $\begin{array}{l}\text { Muscle paralysis } \\
\text { [leaves] }\end{array}$ & [13] \\
\hline & Asclepias mexicana Cav. & $\begin{array}{l}\text { Venenillo } \\
\text { cimarrón }\end{array}$ & Warts & Numbness [leaves] & [12] \\
\hline & $\begin{array}{l}\text { Asclepias oenotheroides } \\
\text { Schltdl. \& Cham }\end{array}$ & Hierba lechosa & Tooth ache & $\begin{array}{l}\text { Numbness, nausea, } \\
\text { and vomiting } \\
\text { [leaves] }\end{array}$ & {$[5]$} \\
\hline & $\begin{array}{c}\text { Asclepias subverticillata (A. } \\
\text { Gray) Vail }\end{array}$ & Hierba lechosa & Snake bite & $\begin{array}{l}\text { Severe diarrhea } \\
\quad \text { [leaves] }\end{array}$ & {$[5]$} \\
\hline \multirow[t]{6}{*}{ Apocynaceae } & Plumeria rubra L.** & Zacalazúchil & $\begin{array}{l}\text { Stomachache, } \\
\text { toothache }\end{array}$ & Dermatitis [latex] & {$[14]$} \\
\hline & Rauvolfia tetraphylla $\mathrm{L}^{* *}$ & Cinco negritos & $\begin{array}{l}\text { Wound healing, } \\
\text { rheumatism }\end{array}$ & $\begin{array}{l}\text { Diarrhea, nausea, } \\
\text { and vomiting, } \\
\text { hypertension, } \\
\text { depression [aerial } \\
\text { parts] }\end{array}$ & [15] \\
\hline & Thevetia ahouai (L.) A. DC. & Bola de venado & $\begin{array}{l}\text { Toothache, } \\
\text { headache }\end{array}$ & $\begin{array}{l}\text { Cardiotoxicity } \\
\text { [fruits and seeds] }\end{array}$ & {$[8]$} \\
\hline & Thevetia gaumeri Hemsl. & Campanilla & Toothache, cancer & $\begin{array}{l}\text { Tooth loss [leaves, } \\
\text { latex] }\end{array}$ & {$[16]$} \\
\hline & $\begin{array}{l}\text { Thevetia peruviana (Pers.) K. } \\
\text { Schum.** }\end{array}$ & Troncomin & Stomachache & $\begin{array}{l}\text { Cardiotoxicity } \\
\text { [leaves] }\end{array}$ & [17] \\
\hline & $\begin{array}{c}\text { Thevetia thevetioides (Kunth) } \\
\text { K. Schum }\end{array}$ & Yoyote & Warts, analgesic & $\begin{array}{l}\text { Cardiotoxicity } \\
\text { [whole plant] }\end{array}$ & [18] \\
\hline Aquifoliaceae & Ilex opaca Aiton & American holly & Digestive & $\begin{array}{l}\text { Cardiotoxicity and } \\
\text { vomiting [fruits] }\end{array}$ & [19] \\
\hline
\end{tabular}


TABle 1: Continued.

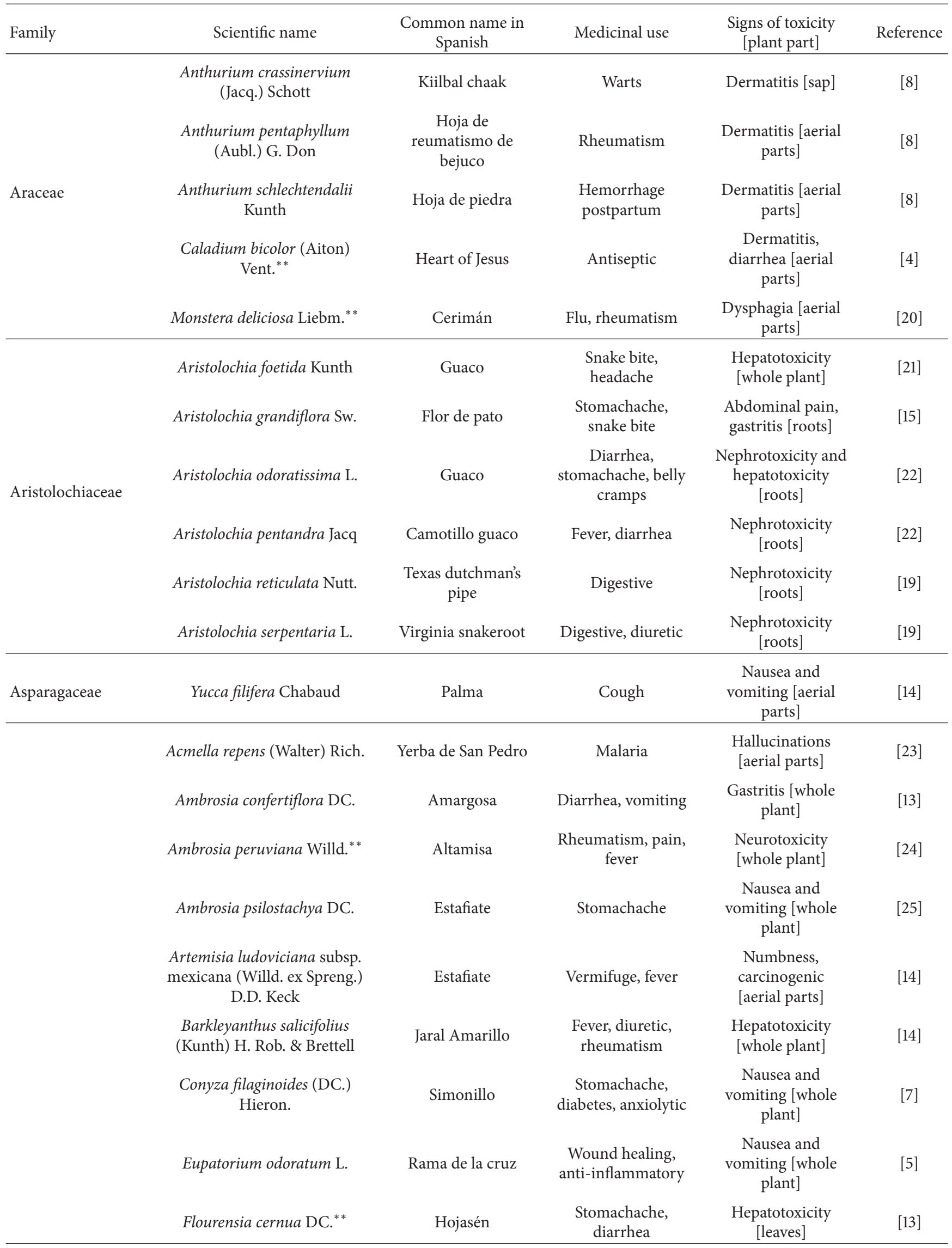


TABle 1: Continued.

\begin{tabular}{|c|c|c|c|c|c|}
\hline Family & Scientific name & $\begin{array}{l}\text { Common name in } \\
\text { Spanish }\end{array}$ & Medicinal use & $\begin{array}{l}\text { Signs of toxicity } \\
\text { [plant part] }\end{array}$ & Reference \\
\hline \multirow{13}{*}{ Asteraceae } & $\begin{array}{l}\text { Gymnosperma glutinosum } \\
\text { (Spreng.) Less. }{ }^{* *}\end{array}$ & Tatalencho & $\begin{array}{l}\text { Diuretic, } \\
\text { rheumatism, } \\
\text { analgesic }\end{array}$ & $\begin{array}{c}\text { Sleepiness, muscle } \\
\text { paralysis [seeds, } \\
\text { leaves] }\end{array}$ & {$[5]$} \\
\hline & $\begin{array}{c}\text { Haplopappus gymnocephalus } \\
\text { DC. }\end{array}$ & Arnica morada & $\begin{array}{l}\text { Body pain, } \\
\text { hemorrhoids }\end{array}$ & $\begin{array}{l}\text { Gastritis [aerial } \\
\text { parts] }\end{array}$ & {$[14]$} \\
\hline & Helenium mexicanum Kunth & Cabezona & Flu & $\begin{array}{c}\text { Gastritis and } \\
\text { vomiting [flowers] }\end{array}$ & {$[15]$} \\
\hline & $\begin{array}{l}\text { Heliopsis longipes (A. Gray) } \\
\text { S.F. Blake** }\end{array}$ & Chilcuague & Analgesic & Narcotic [roots] & {$[26]$} \\
\hline & Montanoa tomentosa Cerv. & Zoapatle & $\begin{array}{l}\text { Rheumatism, } \\
\text { cough, menstrual } \\
\text { colic }\end{array}$ & $\begin{array}{l}\text { Abortifacient, } \\
\text { respiratory failure } \\
\text { [aerial parts] }\end{array}$ & {$[27]$} \\
\hline & $\begin{array}{c}\text { Packera aurea (L.) Á. Löve \& } \\
\text { D. Löve }\end{array}$ & Life root & $\begin{array}{l}\text { Amenorrhea, } \\
\text { menopause and } \\
\text { leucorrhea. }\end{array}$ & $\begin{array}{l}\text { Hepatotoxicity } \\
\text { [aerial parts] }\end{array}$ & {$[19]$} \\
\hline & $\begin{array}{c}\text { Packera candidissima (Greene) } \\
\text { W.A. Weber \& Á. Löve }\end{array}$ & Chuca & Cough & $\begin{array}{l}\text { Hepatotoxicity } \\
\text { [aerial parts] }\end{array}$ & {$[28]$} \\
\hline & Parthenium hysterophorus L.** & Escoba amarga & $\begin{array}{l}\text { Stomachache, } \\
\text { headache }\end{array}$ & $\begin{array}{c}\text { Hypotensive, } \\
\text { bradycardia [whole } \\
\text { plant] }\end{array}$ & {$[29]$} \\
\hline & Parthenium incanum Kunth & Mariola & $\begin{array}{l}\text { Stomachache, } \\
\text { diarrhea }\end{array}$ & $\begin{array}{c}\text { Nausea and } \\
\text { vomiting [whole } \\
\text { plant] }\end{array}$ & {$[13]$} \\
\hline & $\begin{array}{l}\text { Psacalium decompositum (A. } \\
\text { Gray) H. Rob. \& Brettell }\end{array}$ & Matarique & $\begin{array}{l}\text { Diabetes, } \\
\text { rheumatism }\end{array}$ & $\begin{array}{l}\text { Neurotoxicity } \\
\quad \text { [roots }]\end{array}$ & {$[30]$} \\
\hline & Tagetes erecta $\mathrm{L}^{* *}$ & $\begin{array}{l}\text { Flor de muerto } \\
\text { (cempaxochitl) }\end{array}$ & $\begin{array}{l}\text { Diarrhea, } \\
\text { vermifuge, } \\
\text { diabetes, } \\
\text { rheumatism }\end{array}$ & Gastritis [flowers] & {$[31]$} \\
\hline & Tagetes lucida Cav** & Pericón & $\begin{array}{l}\text { Stomachache, } \\
\text { diarrhea, vomit }\end{array}$ & $\begin{array}{l}\text { Abortifacient } \\
\text { [whole plant] }\end{array}$ & {$[32]$} \\
\hline & Zinnia peruviana (L.) L.** & Mal de ojo & $\begin{array}{c}\text { Stomachache, } \\
\text { diarrhea }\end{array}$ & Eye irritant & {$[14]$} \\
\hline \multirow{3}{*}{ Berberidaceae } & $\begin{array}{c}\text { Berberis moranensis Schult. \& } \\
\text { Schult. f. }\end{array}$ & Palo amarillo & Rheumatism & $\begin{array}{c}\text { Numbness, nausea, } \\
\text { and vomiting } \\
\text { [aerial parts] }\end{array}$ & {$[33]$} \\
\hline & $\begin{array}{l}\text { Caulophyllum thalictroides (L.) } \\
\text { Michx.** }\end{array}$ & Blue cohosh & $\begin{array}{l}\text { Dysmenorrhea, } \\
\text { rheumatism }\end{array}$ & $\begin{array}{c}\text { Nausea and } \\
\text { vomiting, gastritis } \\
\text { [seeds and roots] }\end{array}$ & [11] \\
\hline & Podophyllum peltatum L.** & Mayapple & Genital warts & $\begin{array}{c}\text { Altered mental } \\
\text { states, tachypnea, } \\
\text { peripheral } \\
\text { neuropathy, nausea } \\
\text { and vomiting, } \\
\text { hypotension, and } \\
\text { fever [whole plant] }\end{array}$ & {$[19]$} \\
\hline \multirow{2}{*}{ Bignoniaceae } & Crescentia alata Kunth & Cuatecomate & Cough, asthma & $\begin{array}{c}\text { Vomiting, } \\
\text { abdominal pain } \\
\text { [fruit] }\end{array}$ & {$[21]$} \\
\hline & Crescentia cujete $\mathrm{L}^{* *}$ & Güiro & $\begin{array}{l}\text { Cough, } \\
\text { tuberculosis }\end{array}$ & $\begin{array}{l}\text { Abortifacient, } \\
\text { severe diarrhea } \\
\text { [fruits] }\end{array}$ & {$[18]$} \\
\hline
\end{tabular}


TABle 1: Continued.

\begin{tabular}{|c|c|c|c|c|c|}
\hline Family & Scientific name & $\begin{array}{l}\text { Common name in } \\
\text { Spanish }\end{array}$ & Medicinal use & $\begin{array}{l}\text { Signs of toxicity } \\
\text { [plant part] }\end{array}$ & Reference \\
\hline \multirow{2}{*}{ Boraginaceae } & Cordia dentata Poir.** & Uvita & Cough & $\begin{array}{l}\text { Severe diarrhea } \\
\quad \text { [fruits] }\end{array}$ & {$[8]$} \\
\hline & Heliotropium curassavicum L. & Alacrancillo & $\begin{array}{l}\text { Asthma, anemia, } \\
\text { snake bite }\end{array}$ & $\begin{array}{c}\text { Hepatitis [whole } \\
\text { plant] }\end{array}$ & {$[11]$} \\
\hline \multirow{2}{*}{ Bromeliaceae } & Bromelia pinguin $\mathrm{L}$. & Piñuela & Cough & Dermatitis [fruits] & {$[34]$} \\
\hline & $\begin{array}{c}\text { Bromelia plumieri (E. Morren) } \\
\text { L.B. Sm. }\end{array}$ & Timbiriche & Inflammation & Dermatitis [fruits] & {$[8]$} \\
\hline \multirow{3}{*}{ Cactaceae } & Cereus marginatus DC. & $\begin{array}{l}\text { Oregano de } \\
\text { zopilote }\end{array}$ & Rabies & $\begin{array}{l}\text { Cardiotoxicity } \\
\text { [aerial parts] }\end{array}$ & {$[13]$} \\
\hline & $\begin{array}{c}\text { Coryphantha pycnacantha } \\
\text { (Mart.) Lem. }\end{array}$ & Falso peyote & $\begin{array}{l}\text { Rheumatism, } \\
\text { analgesic }\end{array}$ & $\begin{array}{l}\text { Sedation in tongue } \\
\text { [fruit }]\end{array}$ & {$[14]$} \\
\hline & $\begin{array}{l}\text { Lophophora williamsii (Lem. } \\
\text { ex Salm-Dyck) J.M. Coult. }\end{array}$ & Peyote & $\begin{array}{l}\text { Rheumatism, } \\
\text { analgesic }\end{array}$ & $\begin{array}{c}\text { Hallucinations } \\
\text { [whole plant] }\end{array}$ & {$[30]$} \\
\hline \multirow[t]{2}{*}{ Campanulaceae } & Lobelia cardinalis L. & Lobelia & Cough, flu & $\begin{array}{l}\text { Hypothermia, } \\
\text { vomiting, } \\
\text { abdominal pain } \\
\text { [aerial parts] }\end{array}$ & {$[4]$} \\
\hline & Lobelia inflata $\mathrm{L}^{* *}$ & Lobelia & $\begin{array}{l}\text { Asthma, muscle } \\
\text { relaxant }\end{array}$ & $\begin{array}{l}\text { Hypotension } \\
\text { [whole plant] }\end{array}$ & {$[35]$} \\
\hline Canellaceae & Canella winterana (L.) Gaertn. & Cúrbana & $\begin{array}{l}\text { Rheumatism, } \\
\text { stomachache }\end{array}$ & $\begin{array}{c}\text { Edema, } \\
\text { hemorrhage } \\
\text { [whole plant] }\end{array}$ & {$[36]$} \\
\hline \multirow{2}{*}{ Caprifoliaceae } & Lonicera periclymenum $\mathrm{L}$. & Woodbine & Diuretic, cough & $\begin{array}{c}\text { Cardiotoxicity and } \\
\text { neurotoxicity } \\
\text { [fruits] }\end{array}$ & {$[11]$} \\
\hline & $\begin{array}{c}\text { Symphoricarpos albus (L.) S.F. } \\
\text { Blake }\end{array}$ & Snowberry & Tuberculosis & $\begin{array}{l}\text { Nausea and } \\
\text { vomiting, } \\
\text { abdominal pain } \\
\text { [whole plant] }\end{array}$ & [11] \\
\hline \multirow[t]{2}{*}{ Celastraceae } & Celastrus scandens L. & Falsa dulcamara & $\begin{array}{l}\text { Diuretic, } \\
\text { tuberculosis }\end{array}$ & $\begin{array}{l}\text { Gastritis, nausea } \\
\text { and vomiting, } \\
\text { diarrhea [fruit] }\end{array}$ & [11] \\
\hline & Euonymus atropurpureus Jacq. & Wahoo & Purgative & Vomiting [bark] & {$[11]$} \\
\hline \multirow[b]{2}{*}{ Commelinaceae } & Commelina elegans Kunth & Hierba del pollo & Conjunctivitis & $\begin{array}{l}\text { Edema, dermatitis } \\
\text { [whole plant] }\end{array}$ & {$[8]$} \\
\hline & Tradescantia spathacea Sw. & Maguey morado & $\begin{array}{l}\text { Cancer, wound } \\
\text { healing, asthma, } \\
\text { cough }\end{array}$ & Skin burns [sap] & {$[8]$} \\
\hline \multirow{5}{*}{ Convulvulaceae } & $\begin{array}{c}\text { Ipomoea murucoides Roem. \& } \\
\text { Schult. }\end{array}$ & Cazahuate & $\begin{array}{l}\text { Hair loss, wound } \\
\text { healing, cough, } \\
\text { diuretic }\end{array}$ & Gastritis [bark] & {$[37]$} \\
\hline & $\begin{array}{c}\text { Ipomoea purga (Wender.) } \\
\text { Hayne }\end{array}$ & Raíz de Jalapa & Purgative & $\begin{array}{l}\text { Vomiting and } \\
\text { abdominal pain } \\
\text { [roots] }\end{array}$ & {$[15]$} \\
\hline & Ipomoea stans Cav. & Tumbavaqueros & Epileptic seizures & $\begin{array}{l}\text { Neurotoxicity } \\
\text { [roots] }\end{array}$ & {$[38]$} \\
\hline & Ipomoea tricolor Cav. & $\begin{array}{c}\text { Hiedra de flores } \\
\text { grandes }\end{array}$ & Analgesic & $\begin{array}{l}\text { Hallucinations } \\
\text { [aerial parts] }\end{array}$ & {$[14]$} \\
\hline & Turbina corymbosa (L.) Raf. & Flor de pascua & $\begin{array}{l}\text { Fever, wound } \\
\text { healing }\end{array}$ & $\begin{array}{l}\text { Hallucinations } \\
\text { [seeds] }\end{array}$ & {$[4]$} \\
\hline
\end{tabular}


TABle 1: Continued.

\begin{tabular}{|c|c|c|c|c|c|}
\hline Family & Scientific name & $\begin{array}{l}\text { Common name in } \\
\text { Spanish }\end{array}$ & Medicinal use & $\begin{array}{l}\text { Signs of toxicity } \\
\text { [plant part] }\end{array}$ & Reference \\
\hline Coriariaceae & Coriaria ruscifolia $\mathrm{L}$. & Huique & Pneumonia & $\begin{array}{c}\text { Hallucinations } \\
\text { [aerial parts] }\end{array}$ & {$[33]$} \\
\hline Cucurbitaceae & Apodanthera undulata A. Gray & Gualaista & Gastritis & $\begin{array}{c}\text { Vomiting and } \\
\text { abdominal pain } \\
\text { [roots and seeds] }\end{array}$ & {$[14]$} \\
\hline Dioscoreaceae & $\begin{array}{l}\text { Dioscorea floribunda M. } \\
\text { Martens \& Galeotti }\end{array}$ & Barbasco amarillo & $\begin{array}{l}\text { Rheumatism, body } \\
\text { pain }\end{array}$ & $\begin{array}{c}\text { Abortifacient } \\
\text { [roots] }\end{array}$ & {$[8]$} \\
\hline Equisetaceae & Equisetum hyemale L.** & Carricillo & $\begin{array}{l}\text { Abdominal pain, } \\
\text { urinary tract } \\
\text { infections }\end{array}$ & $\begin{array}{l}\text { Hepatotoxicity } \\
\text { [whole plant] }\end{array}$ & [39] \\
\hline \multirow{3}{*}{ Ericaceae } & $\begin{array}{c}\text { Arbutus arizonica (A. Gray) } \\
\text { Sarg. }\end{array}$ & Madroño & Diuretic & $\begin{array}{c}\text { Nausea and } \\
\text { vomiting [fruit] }\end{array}$ & {$[14]$} \\
\hline & $\begin{array}{c}\text { Comarostaphylis discolor } \\
\text { (Hook.) Diggs }\end{array}$ & Madroño & Diuretic & $\begin{array}{c}\text { Nausea and } \\
\text { vomiting [fruit] }\end{array}$ & {$[33]$} \\
\hline & Kalmia latifolia L. & Ivy brush & Syphilis & $\begin{array}{l}\text { Neurotoxicity, } \\
\text { cardiotoxicity } \\
\text { [aerial parts] }\end{array}$ & {$[11]$} \\
\hline & $\begin{array}{c}\text { Acalypha monostachya Cav. } \\
\text { Cav }\end{array}$ & Hierba del cancer & Cancer & Skin burns [latex] & {$[14]$} \\
\hline & $\begin{array}{l}\text { Adelia barbinervis Schltdl. \& } \\
\text { Cham. }\end{array}$ & Espino blanco & Body pain, wounds & $\begin{array}{l}\text { Dermatitis [aerial } \\
\text { parts] }\end{array}$ & {$[8]$} \\
\hline & $\begin{array}{c}\text { Cnidoscolus chayamansa } \\
\text { McVaugh }^{* *}\end{array}$ & Chaya & Diabetes & $\begin{array}{l}\text { Dermatitis [aerial } \\
\text { parts] }\end{array}$ & {$[8]$} \\
\hline & Cnidoscolus souzae McVaugh & Ch'iinchay & Rheumatism & $\begin{array}{c}\text { Dermatitis [aerial } \\
\text { parts] }\end{array}$ & {$[8]$} \\
\hline & $\begin{array}{l}\text { Cnidoscolus urens (L.) } \\
\text { Arthur** }\end{array}$ & Ortiga & Diuretic & $\begin{array}{c}\text { Hypotension, skin } \\
\text { burns, nausea and } \\
\text { vomiting [whole } \\
\text { plant] }\end{array}$ & {$[24]$} \\
\hline & $\begin{array}{c}\text { Croton ciliatoglandulosus } \\
\text { Ortega }\end{array}$ & Hierba de la cruz & Constipation & $\begin{array}{c}\text { Gastritis, excessive } \\
\text { salivation [whole } \\
\text { plant] }\end{array}$ & {$[4]$} \\
\hline & Croton humilis L. & ik'ja'aban & Wounds & $\begin{array}{l}\text { Skin burns [aerial } \\
\text { parts] }\end{array}$ & {$[8]$} \\
\hline & Dalechampia scandens $\mathrm{L}$. & Mo’ol koj & Headache & $\begin{array}{l}\text { Edema, dermatitis } \\
\text { [aerial parts] }\end{array}$ & {$[11]$} \\
\hline \multirow{6}{*}{ Euphorbiaceae } & Euphorbia cotinifolia L. & Lechero rojo & Purgative & Skin burns [seeds] & {$[24]$} \\
\hline & Euphorbia hirta L. ${ }^{* *}$ & $\begin{array}{l}\text { Hierba de la } \\
\text { golondrina }\end{array}$ & Stomachache & $\begin{array}{l}\text { Skin burns [aerial } \\
\text { parts] }\end{array}$ & {$[14]$} \\
\hline & Euphorbia maculata L. & $\begin{array}{l}\text { Hierba de la } \\
\text { golondrina }\end{array}$ & Tooth ache & $\begin{array}{l}\text { Severe diarrhea, } \\
\text { vomiting [seeds] }\end{array}$ & {$[4]$} \\
\hline & Euphorbia prostrata Aiton** & $\begin{array}{l}\text { Hierba de la } \\
\text { golondrina }\end{array}$ & $\begin{array}{l}\text { Pain in the kidney, } \\
\text { wounds, diarrhea }\end{array}$ & $\begin{array}{c}\text { Gastritis, } \\
\text { abdominal pain } \\
\text { [whole plant] }\end{array}$ & {$[31]$} \\
\hline & $\begin{array}{l}\text { Euphorbia pulcherrima Willd. } \\
\text { ex Klotzsch** }\end{array}$ & Noche buena & Wound healing & $\begin{array}{c}\text { Vomiting, } \\
\text { diarrhea, } \\
\text { abdominal pain } \\
\text { [whole plant] }\end{array}$ & {$[40]$} \\
\hline & Euphorbia tithymaloides L. & Redbird flower & $\begin{array}{l}\text { Asthma, skin } \\
\text { cancer, warts }\end{array}$ & $\begin{array}{c}\text { Irritation of the } \\
\text { mouth and throat, } \\
\text { vomiting [whole } \\
\text { plant] }\end{array}$ & {$[20]$} \\
\hline
\end{tabular}


TABle 1: Continued.

\begin{tabular}{|c|c|c|c|c|c|}
\hline Family & Scientific name & $\begin{array}{l}\text { Common name in } \\
\text { Spanish }\end{array}$ & Medicinal use & $\begin{array}{l}\text { Signs of toxicity } \\
\text { [plant part] }\end{array}$ & Reference \\
\hline & Hura crepitans $\mathrm{L} .{ }^{* *}$ & Catahua & Laxative & Skin burns [seeds] & {$[41]$} \\
\hline & Hura polyandra Baill. & Haba & $\begin{array}{l}\text { Stomachache, body } \\
\text { pain, }\end{array}$ & $\begin{array}{c}\text { Skin burns [latex], } \\
\text { nausea and } \\
\text { vomiting, gastritis } \\
\text { [seeds and fruits] }\end{array}$ & {$[15]$} \\
\hline & Jatropha curcas L.** & Piñon & Fever, warts & $\begin{array}{c}\text { Dermatitis, } \\
\text { vomiting, diarrhea } \\
\text { [seeds, leaves] }\end{array}$ & [36] \\
\hline & Jatropha dioica Sessé** & Sangre de grado & $\begin{array}{c}\text { Cancer, } \\
\text { rheumatism, hair } \\
\text { loss, wound } \\
\text { healing }\end{array}$ & $\begin{array}{c}\text { Dermatitis, } \\
\text { vomiting, muscle } \\
\text { paralysis [stem, } \\
\text { fruits] }\end{array}$ & {$[13]$} \\
\hline & Jatropha gossypiifolia L.** & Tua tua & Cough, flu, fever & $\begin{array}{l}\text { Skin burns, } \\
\text { abortifacient } \\
\text { [seeds, leaves] }\end{array}$ & {$[42]$} \\
\hline & Jatropha multifida L. ${ }^{* *}$ & Palmeado & $\begin{array}{l}\text { Wound healing, to } \\
\text { purify blood }\end{array}$ & $\begin{array}{l}\text { Severe diarrhea } \\
\text { [seeds] }\end{array}$ & {$[43]$} \\
\hline & Manihot esculenta Crantz ${ }^{* *}$ & Yuca & $\begin{array}{l}\text { Wound healing, } \\
\text { vermifuge }\end{array}$ & $\begin{array}{c}\text { Poisoning and } \\
\text { neurotoxicity } \\
\text { [leaves] }\end{array}$ & {$[41]$} \\
\hline & Tragia nepetifolia Cav. & Ortiguilla & Diuretic & $\begin{array}{l}\text { Skin burns [Aerial } \\
\text { parts] }\end{array}$ & {$[44]$} \\
\hline & Tragia yucatanensis Millsp. & P'oop'ox & Rheumatism & $\begin{array}{l}\text { Dermatitis [aerial } \\
\text { parts] }\end{array}$ & {$[8]$} \\
\hline & Abrus precatorius $\mathrm{L}^{* *}$ & Semilla de culebra & Diabetes, asthma & $\begin{array}{c}\text { Stomachache, } \\
\text { diarrhea [aerial } \\
\text { parts] }\end{array}$ & {$[4]$} \\
\hline & $\begin{array}{c}\text { Andira inermis (W. Wright) } \\
\text { Kunth ex DC. }\end{array}$ & Yaba & Vermifuge & $\begin{array}{l}\text { Vomiting, fever, } \\
\text { hypotension, } \\
\text { mental confusion, } \\
\text { respiratory } \\
\text { insufficiency [bark] }\end{array}$ & {$[36]$} \\
\hline & Astragalus plattensis Nutt. & Garbancillo & Diuretic & Vomiting [leaves] & {$[26]$} \\
\hline & $\begin{array}{l}\text { Caesalpinia pulcherrima (L.) } \\
\text { Sw.** }\end{array}$ & Clavellina colorada & Fever, pain, cough & $\begin{array}{l}\text { Dermatitis and } \\
\text { neurotoxicity } \\
\text { [Aerial parts] }\end{array}$ & {$[18]$} \\
\hline & $\begin{array}{c}\text { Calliandra grandiflora (L’Hér.) } \\
\text { Benth. }\end{array}$ & Cabello de ángel & Fever & Dermatitis [leaves] & {$[45]$} \\
\hline & Calliandra molinae Standl. & Palo de corcho & Hypertension & $\begin{array}{l}\text { Hepatotoxicity, } \\
\text { hypotension } \\
\text { [leaves] }\end{array}$ & {$[46]$} \\
\hline & Crotalaria pumila Ortega & Tronador & Cough, diabetes & $\begin{array}{l}\text { Abdominal pain, } \\
\text { nausea and } \\
\text { vomiting [whole } \\
\text { plant] }\end{array}$ & {$[14]$} \\
\hline & Crotalaria sagittalis $\mathrm{L}$. & Cocuite & Fever, snake bite & $\begin{array}{c}\text { Anoxia, gastritis, } \\
\text { abdominal pain, } \\
\text { blood in feces } \\
\text { [Aerial parts] }\end{array}$ & {$[4]$} \\
\hline & $\begin{array}{l}\text { Dalea bicolor Humb. \& Bonpl. } \\
\text { ex Willd. }\end{array}$ & Engordacabra & Diarrhea & $\begin{array}{l}\text { Vomiting [aerial } \\
\text { parts] }\end{array}$ & {$[14]$} \\
\hline & Diphysa robinioides Benth. & Flor de gallito & Fever, headache & $\begin{array}{c}\text { Nausea and } \\
\text { vomiting [leaves] }\end{array}$ & {$[47]$} \\
\hline
\end{tabular}


TABle 1: Continued.

\begin{tabular}{|c|c|c|c|c|c|}
\hline Family & Scientific name & $\begin{array}{l}\text { Common name in } \\
\text { Spanish }\end{array}$ & Medicinal use & $\begin{array}{l}\text { Signs of toxicity } \\
\text { [plant part] }\end{array}$ & Reference \\
\hline \multirow{14}{*}{ Fabaceae } & Entada polystachya (L.) DC. & Bejuco de agua & $\begin{array}{l}\text { To promote hair } \\
\text { growth }\end{array}$ & $\begin{array}{c}\text { Abdominal pain } \\
\text { and severe diarrhea } \\
\text { [Fruits }]\end{array}$ & {$[4]$} \\
\hline & $\begin{array}{l}\text { Enterolobium cyclocarpum } \\
\text { (Jacq.) Griseb. }{ }^{* *}\end{array}$ & Cascabel sonaja & $\begin{array}{l}\text { Bronchitis, sore } \\
\text { throat }\end{array}$ & $\begin{array}{c}\text { Severe diarrhea } \\
\text { and abdominal } \\
\text { pain [Aerial parts] }\end{array}$ & {$[4]$} \\
\hline & Erythrina americana Mill** & Colorin & Diuretic & $\begin{array}{l}\text { Immobilization, } \\
\text { hypotension, and } \\
\text { respiratory } \\
\text { paralysis [seeds] }\end{array}$ & {$[15]$} \\
\hline & Erythrina standleyana Krukoff & Cancer & Cancer & $\begin{array}{l}\text { Somnolence, vomit } \\
\text { [aerial parts] }\end{array}$ & {$[8]$} \\
\hline & $\begin{array}{l}\text { Gliricidia sepium (Jacq.) } \\
\text { Kunth ex Walp }\end{array}$ & Matarratón & Vermifuge & $\begin{array}{c}\text { Nausea and } \\
\text { vomiting [roots, } \\
\text { leaves, seeds] }\end{array}$ & {$[24]$} \\
\hline & Indigofera microcarpa Desv. & $\begin{array}{l}\text { Yaga-cohui- } \\
\text { pichacha }\end{array}$ & Purgative & $\begin{array}{l}\text { Severe diarrhea } \\
\quad \text { [leaves] }\end{array}$ & {$[4]$} \\
\hline & Indigofera suffruticosa Mill. ${ }^{* *}$ & Añil & Vermifuge & $\begin{array}{l}\text { Severe diarrhea } \\
\quad \text { [leaves] }\end{array}$ & {$[4]$} \\
\hline & $\begin{array}{l}\text { Leucaena esculenta (Moc. \& } \\
\text { Sessé ex DC.) Benth. }\end{array}$ & Guaje & Wound healing & $\begin{array}{c}\text { Nausea and } \\
\text { vomiting [seeds] }\end{array}$ & {$[48]$} \\
\hline & $\begin{array}{l}\text { Myroxylon pereirae (Royle) } \\
\text { Klotzsch }^{* *}\end{array}$ & Indian balsam & $\begin{array}{c}\text { Burns, wounds and } \\
\text { ulcers }\end{array}$ & $\begin{array}{l}\text { Allergies, contact } \\
\text { urticaria and } \\
\text { dermatitis [resin] }\end{array}$ & {$[49]$} \\
\hline & Phaseolus lunatus L. & Frijol ancho & Fever, headache & $\begin{array}{c}\text { Seizures, } \\
\text { immobilization } \\
\text { [whole plant] }\end{array}$ & {$[4]$} \\
\hline & Prosopis juliflora (Sw.) DC. & Mezquite & Fever, diabetes & $\begin{array}{c}\text { Nausea and } \\
\text { vomiting [seeds] }\end{array}$ & {$[4]$} \\
\hline & Robinia pseudoacacia L. & Black locust & Diuretic, laxative & $\begin{array}{c}\text { Anorexia, } \\
\text { hypothermia, } \\
\text { dyspnoea [bark, } \\
\text { leaves and seeds] }\end{array}$ & {$[4]$} \\
\hline & $\begin{array}{l}\text { Senna multiglandulosa (Jacq.) } \\
\text { H.S. Irwin \& Barneby }\end{array}$ & Parral & Diabetes & $\begin{array}{l}\text { Abortifacient } \\
\text { [fruit] }\end{array}$ & {$[33]$} \\
\hline & Senna occidentalis (L.) Link ${ }^{* *}$ & Frijolillo & Fever & $\begin{array}{c}\text { Gastritis, } \\
\text { dermatitis, and } \\
\text { conjunctivitis } \\
\text { [fruit] }\end{array}$ & {$[4]$} \\
\hline Garryaceae & Garrya ovata Benth. & Cuauhchichic & Diarrhea & $\begin{array}{l}\text { Muscle paralysis } \\
\text { [bark] }\end{array}$ & {$[26]$} \\
\hline Gelsemiaceae & $\begin{array}{c}\text { Gelsemium sempervirens (L.) J. } \\
\text { St.-Hil.* }{ }^{*}\end{array}$ & Retama & $\begin{array}{l}\text { Stomachache, } \\
\text { asthma, headache, } \\
\text { rheumatism }\end{array}$ & $\begin{array}{c}\text { Sedative, vertigo, } \\
\text { hypotension, } \\
\text { blurred vision } \\
\text { [whole plant] }\end{array}$ & {$[10]$} \\
\hline \multirow[t]{4}{*}{ Gesneriaceae } & $\begin{array}{c}\text { Moussonia deppeana (Schltdl. } \\
\text { \& Cham.) Hanst.** }\end{array}$ & Cacahuapaxtle & Diuretic, gastritis & $\begin{array}{l}\text { Abortifacient } \\
\text { [aerial parts] }\end{array}$ & {$[50]$} \\
\hline & Hedeoma drummondii Benth. & $\begin{array}{l}\text { Drummond's false } \\
\text { pennyroyal }\end{array}$ & Muscle relaxing & $\begin{array}{l}\text { Abortifacient } \\
\text { [whole plant] }\end{array}$ & {$[26]$} \\
\hline & Hedeoma pulegioides (L.) Pers. & $\begin{array}{l}\text { American } \\
\text { pennyroyal }\end{array}$ & $\begin{array}{l}\text { Antispasmodic, } \\
\text { pneumonia }\end{array}$ & $\begin{array}{l}\text { Abortifacient, } \\
\text { kidney toxicity } \\
\text { [aerial parts] }\end{array}$ & {$[19]$} \\
\hline & Salvia leucantha Cav & Lana & $\begin{array}{l}\text { Cough, } \\
\text { stomachache }\end{array}$ & $\begin{array}{l}\text { Abortifacient } \\
\text { [aerial parts] }\end{array}$ & {$[27]$} \\
\hline
\end{tabular}


TABle 1: Continued.

\begin{tabular}{|c|c|c|c|c|c|}
\hline Family & Scientific name & $\begin{array}{l}\text { Common name in } \\
\text { Spanish }\end{array}$ & Medicinal use & $\begin{array}{l}\text { Signs of toxicity } \\
\text { [plant part] }\end{array}$ & Reference \\
\hline \multirow[t]{2}{*}{ Lamiaceae } & Satureja brownei (Sw.) Briq. & Poleo & Colic, cough & $\begin{array}{c}\text { Nausea and } \\
\text { vomiting, } \\
\text { dermatitis, } \\
\text { bleeding [whole } \\
\text { plant] }\end{array}$ & {$[24]$} \\
\hline & Scutellaria lateriflora L. & Scullcap & $\begin{array}{l}\text { Nervousness, } \\
\text { headache, fever, } \\
\text { anxiety }\end{array}$ & $\begin{array}{l}\text { Giddiness, stupor, } \\
\text { confusion, } \\
\text { twitching of the } \\
\text { limbs, intermission } \\
\text { of the pulse [whole } \\
\text { plant] }\end{array}$ & {$[19]$} \\
\hline Loasaceae & Mentzelia hispida Willd. & Pegajilla & $\begin{array}{l}\text { Rheumatism, } \\
\text { anemia }\end{array}$ & Vomiting [resin] & {$[14]$} \\
\hline Loranthaceae & $\begin{array}{l}\text { Psittacanthus calyculatus } \\
\text { (DC.) G. Don }{ }^{* *}\end{array}$ & Muerdago o injerto & $\begin{array}{l}\text { Hypertension, } \\
\text { seizures, } \\
\text { rheumatism, } \\
\text { wound healing }\end{array}$ & $\begin{array}{c}\text { Nausea and } \\
\text { vomiting [whole } \\
\text { plant] }\end{array}$ & {$[26]$} \\
\hline Lythraceae & Cuphea aequipetala Cav.** & Hierba del cáncer & $\begin{array}{l}\text { Cancer, wound } \\
\text { healing }\end{array}$ & $\begin{array}{c}\text { Numbness, nausea } \\
\text { and vomiting } \\
\text { [aerial parts] }\end{array}$ & {$[10]$} \\
\hline Magnoliaceae & Magnolia grandiflora L.** & Magnolia & $\begin{array}{l}\text { Nervousness, } \\
\text { menstrual colics }\end{array}$ & Dermatitis [leaves] & {$[51]$} \\
\hline Malpighiaceae & Malpighia glabra L. & Acerola & Dysentery, fever & Dermatitis [fruits] & [19] \\
\hline \multirow{2}{*}{ Malvaceae } & $\begin{array}{l}\text { Ceiba pentandra (L.) } \\
\text { Gaertn.** }\end{array}$ & Ceiba & $\begin{array}{l}\text { Diuretic, cough, } \\
\text { fever }\end{array}$ & Dermatitis [seeds] & {$[24]$} \\
\hline & Tilia mexicana Schltdl. ${ }^{* *}$ & Tilia & $\begin{array}{l}\text { Nervousness, } \\
\text { menstrual pain }\end{array}$ & $\begin{array}{l}\text { Hepatotoxicity } \\
\text { [flower] }\end{array}$ & {$[39]$} \\
\hline Marantaceae & Thalia geniculata $\mathrm{L}$. & Kento & $\begin{array}{c}\text { Anaemia, } \\
\text { hemorrhoids }\end{array}$ & $\begin{array}{l}\text { Edema, gastritis } \\
\text { [aerial parts] }\end{array}$ & {$[8]$} \\
\hline Martyniaceae & Martynia annua L.** & Uña de gato & Snake bite & $\begin{array}{c}\text { Nausea and } \\
\text { vomiting [seeds] }\end{array}$ & {$[18]$} \\
\hline \multirow[b]{2}{*}{ Melanthiaceae } & $\begin{array}{l}\text { Veratrum californicum } \\
\text { Durand }^{* *}\end{array}$ & California corn lily & Cancer & $\begin{array}{l}\text { Neurotoxicity } \\
\text { [whole plant] }\end{array}$ & {$[11]$} \\
\hline & Trillium erectum $\mathrm{L}$. & Bethroot & $\begin{array}{c}\text { To prevent } \\
\text { obstetric } \\
\text { hemorrhage }\end{array}$ & Skin burns [leaves] & {$[19]$} \\
\hline Menispermaceae & Menispermum canadense $\mathrm{L}$. & Canada moonseed & Warts & $\begin{array}{l}\text { Cardiotoxicity } \\
\text { [fruits] }\end{array}$ & [11] \\
\hline Myrtaceae & Pimenta dioica (L.) Merr. ${ }^{* *}$ & Pimiento & $\begin{array}{l}\text { Rheumatism, } \\
\text { stomachache }\end{array}$ & $\begin{array}{l}\text { Neurotoxicity } \\
\text { [whole plant] }\end{array}$ & {$[19]$} \\
\hline Nartheciaceae & Aletris farinosa L. & Unicorn root & $\begin{array}{l}\text { Laxative, diarrhea, } \\
\text { rheumatism }\end{array}$ & $\begin{array}{l}\text { Narcotic [whole } \\
\text { plant] }\end{array}$ & [19] \\
\hline Nyctaginacea & Mirabilis jalapa $\mathrm{L}^{* *}$ & Maravilla & $\begin{array}{l}\text { Rheumatism, } \\
\text { stomachache, fever }\end{array}$ & $\begin{array}{c}\text { Severe diarrhea } \\
\text { [roots and seeds] }\end{array}$ & {$[4]$} \\
\hline Oxalidaceae & $\begin{array}{c}\text { Oxalis alpina (Rose) Rose ex } \\
\text { R. Knuth }\end{array}$ & Acedera & Gastritis & $\begin{array}{l}\text { Poisoning [whole } \\
\text { plant] }\end{array}$ & {$[7]$} \\
\hline \multirow[t]{2}{*}{ Papaveraceae } & Argemone mexicana $\mathrm{L}^{* *}$ & Cardo santo & $\begin{array}{l}\text { Wound healing, } \\
\text { fever, diuretic, } \\
\text { analgesic }\end{array}$ & $\begin{array}{l}\text { Dermatitis, } \\
\text { abortifacient } \\
\text { immobilizing, } \\
\text { neurotoxicity } \\
\text { [whole plant] }\end{array}$ & {$[35]$} \\
\hline & Sanguinaria canadensis $\mathrm{L}^{* *}$ & Bloodroot & $\begin{array}{l}\text { Skin cancer, polyps } \\
\text { and warts }\end{array}$ & Narcotic [root] & {$[19]$} \\
\hline
\end{tabular}


TABle 1: Continued.

\begin{tabular}{|c|c|c|c|c|c|}
\hline Family & Scientific name & $\begin{array}{l}\text { Common name in } \\
\text { Spanish }\end{array}$ & Medicinal use & $\begin{array}{l}\text { Signs of toxicity } \\
\text { [plant part] }\end{array}$ & Reference \\
\hline \multirow{3}{*}{ Passifloraceae } & Passiflora caerulea L. & Pasionaria azul & Epilepsy, anxiolytic & $\begin{array}{c}\text { Nausea and } \\
\text { vomiting, dizziness } \\
\text { [flower] }\end{array}$ & {$[24]$} \\
\hline & Passiflora edulis Sims ${ }^{* *}$ & Maracuya & Relaxing & $\begin{array}{l}\text { Hallucinations, } \\
\text { dizziness, } \\
\text { confusion, ataxia, } \\
\text { nausea and } \\
\text { vomiting, } \\
\text { drowsiness, and } \\
\text { tachycardia; } \\
\text { [flower] }\end{array}$ & {$[39,41]$} \\
\hline & Passiflora quadrangularis L. & Badea & Vermifuge, obesity & $\begin{array}{c}\text { Nausea and } \\
\text { vomiting, dizziness } \\
\text { [leaves and seeds] }\end{array}$ & {$[24]$} \\
\hline Petiveriaceae & Rivina humilis L.** & Coralillo & $\begin{array}{c}\text { Varicose veins, } \\
\text { snake bite, wound } \\
\text { healing, } \\
\text { stomachache }\end{array}$ & $\begin{array}{c}\text { Nausea and } \\
\text { vomiting, } \\
\text { abdominal pain } \\
\text { [whole plant] }\end{array}$ & {$[11]$} \\
\hline \multirow{3}{*}{ Phytolaccaceae } & Phytolacca americana L. & Hierba carmine & Warts & $\begin{array}{l}\text { Blurred vision, } \\
\text { vomit, vertigo } \\
\text { [whole plant] }\end{array}$ & {$[52]$} \\
\hline & Phytolacca icosandra L.** & Mazorquilla & $\begin{array}{l}\text { Cancer, vermifuge, } \\
\text { rheumatism }\end{array}$ & $\begin{array}{l}\text { Blurred vision, } \\
\text { vomiting, [roots] }\end{array}$ & {$[14]$} \\
\hline & $\begin{array}{c}\text { Phytolacca rivinoides Kunth \& } \\
\text { C.D. Bouché }\end{array}$ & Mazorquilla & $\begin{array}{l}\text { Headache, wound } \\
\text { healing, vermifuge }\end{array}$ & $\begin{array}{l}\text { Blurred vision, } \\
\text { vomit, vertigo } \\
\text { [whole plant] }\end{array}$ & {$[30]$} \\
\hline Plantaginaceae & Scoparia dulcis $\mathrm{L}^{* *}$ & Culantrillo & $\begin{array}{c}\text { Diarrhea, } \\
\text { stomachache, } \\
\text { asthma, } \\
\text { nervousness }\end{array}$ & $\begin{array}{l}\text { Hepatotoxicity } \\
\text { [whole plant] }\end{array}$ & {$[39]$} \\
\hline Plumbaginaceae & Plumbago pulchella Boiss. & Jiricua & $\begin{array}{l}\text { Diabetes, wound } \\
\text { healing }\end{array}$ & $\begin{array}{c}\text { Skin burns, } \\
\text { vomiting [whole } \\
\text { plant] }\end{array}$ & {$[14]$} \\
\hline \multirow{3}{*}{ Polygalaceae } & $\begin{array}{c}\text { Monnina schlechtendaliana D. } \\
\text { Dietr. }\end{array}$ & Aguacatillo & Dehydration & $\begin{array}{c}\text { Nausea and } \\
\text { vomiting [fruit] }\end{array}$ & {$[33]$} \\
\hline & Polygala senega L. & rattlesnake root & Cough, diuretic & Gastritis [roots] & [19] \\
\hline & Rumex hymenosepalus Torr. ${ }^{* *}$ & Canaigre & Wound healing & $\begin{array}{c}\text { Vomiting, } \\
\text { abdominal pain } \\
\text { [Aerial parts] }\end{array}$ & {$[19]$} \\
\hline \multirow{5}{*}{ Ranunculaceae } & Actaea alba (L.) Mill. & White cohosh & $\begin{array}{l}\text { Arthritis, } \\
\text { rheumatism, } \\
\text { dysmenorrhea }\end{array}$ & $\begin{array}{c}\text { Headache, } \\
\text { vomiting, delirium, } \\
\text { circulatory failure } \\
\text { [whole plant] }\end{array}$ & {$[19]$} \\
\hline & Actaea rubra (Aiton) Willd. & Baneberry & Dysmenorrhea & $\begin{array}{l}\text { Vomiting, } \\
\text { abdominal pain, } \\
\text { salivation [fruits } \\
\text { and roots] }\end{array}$ & {$[11]$} \\
\hline & Anemone canadensis L. & Meadow anemone & $\begin{array}{l}\text { Body pain and } \\
\text { wound healing }\end{array}$ & $\begin{array}{c}\text { Salivation, } \\
\text { abdominal pain, } \\
\text { and salivation } \\
\text { [whole plant] }\end{array}$ & {$[11]$} \\
\hline & $\begin{array}{l}\text { Cimicifuga racemosa (L.) } \\
\text { Nutt. }^{* *}\end{array}$ & Baneberry & $\begin{array}{l}\text { To manage some } \\
\text { symptoms of } \\
\text { menopause }\end{array}$ & $\begin{array}{l}\text { Vomiting, } \\
\text { abdominal pain } \\
\text { [fruit] }\end{array}$ & {$[19]$} \\
\hline & Clematis dioica L. & Barba de chivo & $\begin{array}{l}\text { Rheumatism, } \\
\text { cough, diuretic }\end{array}$ & Skin burns [leaves] & {$[10]$} \\
\hline
\end{tabular}


TABle 1: Continued.

\begin{tabular}{|c|c|c|c|c|c|}
\hline Family & Scientific name & $\begin{array}{l}\text { Common name in } \\
\text { Spanish }\end{array}$ & Medicinal use & $\begin{array}{l}\text { Signs of toxicity } \\
\text { [plant part] }\end{array}$ & Reference \\
\hline & Clematis virginiana $\mathrm{L}$. & Old man's beard & $\begin{array}{c}\text { For skin disorders } \\
\text { (sores, cuts), } \\
\text { itching and } \\
\text { venereal eruptions }\end{array}$ & $\begin{array}{c}\text { Dizziness, } \\
\text { confusion, profuse } \\
\text { salivation [leaves] }\end{array}$ & {$[19]$} \\
\hline & Hydrastis canadensis $\mathrm{L}^{* *}$ & Sello dorado & Laxative & $\begin{array}{c}\text { Gastritis, } \\
\text { abortifacient } \\
\text { [rhizome] }\end{array}$ & {$[35]$} \\
\hline & $\begin{array}{l}\text { Ranunculus geoides Humb. } \\
\text { Bonpl. \& Kunth ex DC }\end{array}$ & Pata de león & Cough & $\begin{array}{l}\text { Skin burns [seeds } \\
\text { and fruits] }\end{array}$ & {$[30]$} \\
\hline & Thalictrum strigillosum Hemsl. & Hierba del zorro & Cough & $\begin{array}{c}\text { Nausea and } \\
\text { vomiting [whole } \\
\text { plant] }\end{array}$ & [7] \\
\hline \multirow{3}{*}{ Rhamnaceae } & $\begin{array}{l}\text { Karwinskia humboldtiana } \\
\text { (Schult.) Zucc. }{ }^{* *}\end{array}$ & Tullidora & Wound healing & $\begin{array}{l}\text { Immobilization, } \\
\text { abortifacient [fruit] }\end{array}$ & {$[53]$} \\
\hline & Karwinskia mollis Schltdl. & Capulín & Wound healing & $\begin{array}{l}\text { Immobilization } \\
\text { [fruit] }\end{array}$ & {$[54]$} \\
\hline & Rhamnus kcalifornica Eschsch & $\begin{array}{l}\text { California } \\
\text { buckthorn }\end{array}$ & Laxative & $\begin{array}{l}\text { Gastritis [fruit and } \\
\text { bark] }\end{array}$ & {$[11]$} \\
\hline Rosaceae & Prunus serotina Ehrh. & Capulín blanco & $\begin{array}{l}\text { Cough, diarrhea, } \\
\text { abdominal pain }\end{array}$ & $\begin{array}{l}\text { Spasm, nausea and } \\
\text { vomiting [leaves } \\
\text { and seeds] }\end{array}$ & [7] \\
\hline \multirow[b]{3}{*}{ Rubarwiaceae } & $\begin{array}{l}\text { Carapichea ipecacuanha } \\
\text { (Brot.) L. Andersson }\end{array}$ & Ipecac & Dysentery & $\begin{array}{l}\text { Rhinitis or asthma } \\
\text { [whole plant] }\end{array}$ & {$[19]$} \\
\hline & Cephalanthus occidentalis L. & Guayabillo & Fever & $\begin{array}{l}\text { Vomiting, seizures, } \\
\text { anemia [bark] }\end{array}$ & {$[4]$} \\
\hline & Cinchona pubescens Vahl** & Quino & $\begin{array}{l}\text { Malaria, varicose } \\
\text { veins, internal } \\
\text { hemorrhoids }\end{array}$ & $\begin{array}{l}\text { Hypoglycemia, } \\
\text { hematologic } \\
\text { disorders, } \\
\text { urticaria, contact } \\
\text { dermatitis, and } \\
\text { other } \\
\text { hypersensitivity } \\
\text { reactions. }\end{array}$ & [19] \\
\hline \multirow{3}{*}{ Rutaceae } & $\begin{array}{l}\text { Casimiroa edulis La Llave \& } \\
\text { Lex. }^{* *}\end{array}$ & Matasanos & $\begin{array}{l}\text { Hypertension, } \\
\text { diabetes, } \\
\text { rheumatism }\end{array}$ & $\begin{array}{l}\text { Hepatotoxicity, } \\
\text { peptic ulcer, } \\
\text { hypotensive } \\
\text { [leaves] }\end{array}$ & {$[46]$} \\
\hline & Ruta chalepensis L.** & Ruda & Analgesic & $\begin{array}{l}\text { Dermatitis, } \\
\text { abortifacient } \\
\text { [aerial parts] }\end{array}$ & {$[18]$} \\
\hline & Zanthoxylum fagara (L.) Sarg. & Colima & Nervousness & Narcotic [leaves] & [26] \\
\hline \multirow{3}{*}{ Santalaceae } & $\begin{array}{l}\text { Phoradendron bolleanum } \\
\text { (Seem.) Eichler }\end{array}$ & Muerdago & Diuretic & $\begin{array}{c}\text { Nausea and } \\
\text { vomiting [leaves } \\
\text { and seeds] }\end{array}$ & {$[55]$} \\
\hline & $\begin{array}{l}\text { Phoradendron quadrangulare } \\
\text { (Kunth) Griseb. }\end{array}$ & Muerdago & Cancer & $\begin{array}{c}\text { Nausea and } \\
\text { vomiting, } \\
\text { dehydration [aerial } \\
\text { parts] }\end{array}$ & {$[11]$} \\
\hline & $\begin{array}{l}\text { Phoradendron serotinum } \\
\text { (Raf.) M.C. Johnst.* }\end{array}$ & Muerdago & Cancer, diabetes & $\begin{array}{c}\text { Nausea and } \\
\text { vomiting, } \\
\text { abdominal pain, } \\
\text { dehydration [aerial } \\
\text { parts] }\end{array}$ & {$[11]$} \\
\hline
\end{tabular}


TABle 1: Continued.

\begin{tabular}{|c|c|c|c|c|c|}
\hline Family & Scientific name & $\begin{array}{l}\text { Common name in } \\
\text { Spanish }\end{array}$ & Medicinal use & $\begin{array}{l}\text { Signs of toxicity } \\
\text { [plant part] }\end{array}$ & Reference \\
\hline Sapindaceae & Sapindus saponaria L.** & Jaboncillo & Diuretic & Skin burns [seeds] & {$[24]$} \\
\hline Sapotaceae & $\begin{array}{l}\text { Pouteria sapota (Jacq.) H.E. } \\
\text { Moore \& Stearn }{ }^{* *}\end{array}$ & Zapote & To eliminate louse & $\begin{array}{c}\text { Nausea and } \\
\text { vomiting, dizziness } \\
{[\text { seeds }]}\end{array}$ & {$[35]$} \\
\hline Scrophulariaceae & Buddleja marrubiifolia Benth. & Azafran de campo & Diuretic & $\begin{array}{l}\text { Neurotoxicity } \\
\text { [seeds] }\end{array}$ & {$[26]$} \\
\hline \multirow{2}{*}{ Simaroubaceae } & Picrasma excelsa (Sw.) Planch. & Palo Amarillo & $\begin{array}{l}\text { Stomachache, } \\
\text { diabetes }\end{array}$ & $\begin{array}{l}\text { Hypotension } \\
\text { [bark] }\end{array}$ & {$[35]$} \\
\hline & Castela tortuosa Liebm. & Chaparro amargo & Fever, amebas & $\begin{array}{l}\text { Hepatotoxicity } \\
\text { [stem] }\end{array}$ & {$[37]$} \\
\hline Smilacaceae & Smilax aristolochiifolia Mill. & Zarzaparilla & Syphilis, psoriasis & $\begin{array}{c}\text { Gastritis [whole } \\
\text { plant] }\end{array}$ & {$[19]$} \\
\hline \multirow{10}{*}{ Solanaceae } & Capsicum annuum $\mathrm{L}^{* *}$ & Chile & Analgesic & $\begin{array}{l}\text { Dermatitis by } \\
\text { rubbing or } \\
\text { gastritis, } \\
\text { hemorrhoids, and } \\
\text { colitis by oral } \\
\text { administration } \\
\text { [seeds, fruits] }\end{array}$ & {$[35]$} \\
\hline & $\begin{array}{l}\text { Cestrum fasciculatum } \\
\text { (Schltdl.) Miers }\end{array}$ & Hierba del perro & Vomiting & $\begin{array}{c}\text { Nausea and } \\
\text { vomiting, dizziness } \\
\text { [aerial parts] }\end{array}$ & {$[10]$} \\
\hline & Cestrum nocturnum $\mathrm{L}$. & Dama de noche & $\begin{array}{l}\text { Headache, } \\
\text { stomachache }\end{array}$ & $\begin{array}{c}\text { tachycardia, } \\
\text { dyspnea, fever, } \\
\text { hallucinations } \\
\text { [leaves] }\end{array}$ & {$[4]$} \\
\hline & Datura inoxia Miller.** & Toloache & $\begin{array}{l}\text { Diabetes, asthma, } \\
\text { wound healing }\end{array}$ & $\begin{array}{c}\text { Narcotic, anorexic, } \\
\text { cardiotoxicity, } \\
\text { blurred vision } \\
\text { [seeds] }\end{array}$ & {$[15]$} \\
\hline & Solanum americanum Mill** & Quelite mora & $\begin{array}{l}\text { Headache, wound } \\
\text { healing }\end{array}$ & $\begin{array}{c}\text { Dermatitis, } \\
\text { vomiting, severe } \\
\text { diarrhea, paralysis } \\
\text { [fruits] }\end{array}$ & {$[29]$} \\
\hline & Solanum elaeagnifolium Cav. & Trompillo & Rattlesnake bite & $\begin{array}{l}\text { Dermatitis [whole } \\
\text { plant] }\end{array}$ & {$[13]$} \\
\hline & Solanum mammosum L. & Chichigua & Diuretic, cough & $\begin{array}{c}\text { Narcotic, } \\
\text { cardiotoxicity } \\
\text { [fruits] }\end{array}$ & {$[35]$} \\
\hline & $\begin{array}{l}\text { Solanum nigrescens } \mathrm{M} . \\
\text { Martens \& Galeotti** }\end{array}$ & Hierba mora & Fever, rheumatism & $\begin{array}{l}\text { Immobilization } \\
\text { [leaves and seeds] }\end{array}$ & [7] \\
\hline & Solanum rostratum Dunal & Duraznillo & $\begin{array}{c}\text { Diuretic, } \\
\text { stomachache, } \\
\text { diarrhea }\end{array}$ & $\begin{array}{l}\text { Dermatitis [aerial } \\
\text { parts] }\end{array}$ & {$[13]$} \\
\hline & Witheringia solanacea L'Hér. & Merengena & To purify blood & $\begin{array}{c}\text { Nausea and } \\
\text { vomiting [leaves } \\
\text { and seeds] }\end{array}$ & {$[47]$} \\
\hline \multirow[t]{2}{*}{ Urticaceae } & $\begin{array}{c}\text { Urera baccifera (L.) Gaudich. } \\
\text { ex Wedd.** }\end{array}$ & Ortiga brava & $\begin{array}{c}\text { Diuretic, } \\
\text { rheumatism, body } \\
\text { pain }\end{array}$ & $\begin{array}{l}\text { Dermatitis, edema } \\
\text { [aerial parts] }\end{array}$ & [11] \\
\hline & Urtica mexicana Liebm. & Ortiga & $\begin{array}{l}\text { Diabetes, } \\
\text { rheumatism }\end{array}$ & $\begin{array}{l}\text { Skin burns [aerial } \\
\text { parts] }\end{array}$ & {$[10]$} \\
\hline
\end{tabular}


TABLE 1: Continued.

\begin{tabular}{|c|c|c|c|c|c|}
\hline Family & Scientific name & $\begin{array}{c}\text { Common name in } \\
\text { Spanish }\end{array}$ & Medicinal use & $\begin{array}{l}\text { Signs of toxicity } \\
\text { [plant part] }\end{array}$ & Reference \\
\hline \multirow{3}{*}{ Verbenaceae } & Duranta repens L. & Mohuite de huerto & $\begin{array}{c}\text { To purify blood, } \\
\text { fever }\end{array}$ & $\begin{array}{c}\text { Nausea and } \\
\text { vomiting, seizures } \\
\text { [flowers] }\end{array}$ & {$[4]$} \\
\hline & Lantana camara L.** & $\begin{array}{l}\text { Hierba de San } \\
\text { Pedro }\end{array}$ & $\begin{array}{l}\text { Stomachache, } \\
\text { diarrhea, } \\
\text { rheumatism }\end{array}$ & $\begin{array}{c}\text { Hepatotoxicity, } \\
\text { nausea, and } \\
\text { vomiting [aerial } \\
\text { parts] }\end{array}$ & {$[52]$} \\
\hline & Lippia dulcis Trevir. & Hierbabuena dulce & $\begin{array}{l}\text { Cough, diarrhea, } \\
\text { stomachache }\end{array}$ & $\begin{array}{l}\text { Vertigo, } \\
\text { hypotension [aerial } \\
\text { parts] }\end{array}$ & {$[18]$} \\
\hline \multirow[b]{2}{*}{ Zygophyllaceae } & Larrea divaricata Cav.** & Chaparral & $\begin{array}{l}\text { Rheumatism, } \\
\text { tuberculosis, snake } \\
\text { bite }\end{array}$ & $\begin{array}{l}\text { Hepatotoxicity } \\
\text { [aerial parts] }\end{array}$ & {$[56]$} \\
\hline & $\begin{array}{l}\text { Larrea tridentata (DC.) } \\
\text { Coville }^{* *}\end{array}$ & Gobernadora & Diabetes, diuretic & $\begin{array}{l}\text { Hepatotoxicity, } \\
\text { nausea and } \\
\text { vomiting, } \\
\text { abortifacient, } \\
\text { gastritis [aerial } \\
\text { parts] }\end{array}$ & {$[37]$} \\
\hline
\end{tabular}

** indicates plant with toxicological information obtained from preclinical or clinical studies.

\section{Toxicology}

4.1. In Vitro Studies. The Artemia salina (brine shrimp) bioassay has been widely used for the analysis of acute toxicity in vitro. Although there are no range values to consider an extract or compound as toxic in the brine shrimp test, vincristine, the positive control for toxicity, has a lethal concentration $50\left(\mathrm{LC}_{50}\right)=0.91 \mu \mathrm{g} / \mathrm{ml}$ [76]. Considering this value, plant extracts or compounds with $\mathrm{LC}_{50}$ values 1000 fold higher than vincristine could be considered nontoxic.

The following plant extracts have been tested for their in vitro toxicology using the brine shrimp test and had $\mathrm{LC}_{50}$ values higher than $1000 \mu \mathrm{g} / \mathrm{ml}$. The ethyl acetate fraction of Solanum nigrescens aerial parts [77], the ethanol extract of Ambrosia peruviana whole plant [78], the aqueous extract of Jatropha gossypifolia aerial parts [79], the methanol extract of Jatropha dioica leaves [80], the aqueous extract of Cnidoscolus urens whole plant [79], the ethanol extract of Crescentia cujete fruits [81], the aqueous extract of Enterolobium cyclocarpum bark [82], and the ethanol extract of Cordia dentata leaves and their fractions [83].

The plant extract and compounds that could be considered dangerous $\left(\mathrm{LC}_{50}=100-1000 \mu \mathrm{g} / \mathrm{ml}\right)$ include the following: methanol and hexane proportions derived from a hexane extract of Gymnosperma glutinosum aerial parts [84], the ethyl acetate extracts of Monstera deliciosa branches [85], and icosandrin, a cyclic homoflavonoid isolated from Phytolacca icosandra [86].

The plant extract and compounds that could be considered toxic $\left(\mathrm{LC}_{50}=10-100 \mu \mathrm{g} / \mathrm{ml}\right)$ include the following: the ethyl acetate extracts of Monstera deliciosa leaves [85], the ethanol extract of Solanum americanum fruits [87], the ethanol extract of Scoparia dulcis aerial parts [76], the methanol extract of Enterolobium cyclocarpum leaves [88], the ethanol extract of Pimenta dioica leaves [89], and the hydroalcoholic extract of Sanguinaria canadensis whole plant [90]. None of the plant extracts or compounds included in this review were considered highly toxic $\left(\mathrm{LC}_{50}<10 \mu \mathrm{g} / \mathrm{ml}\right)$.

4.1.1. Cytotoxicity. Other plant extracts and their compounds have been tested in other in vitro models, including cytotoxicity test in nontumorigenic cells, genotoxicity using the comet assay on lymphocytes, and the mutagenic test using lymphocytes or Salmonella spp. The positive controls for cytotoxicity in nontumorigenic cells include cisplatin and Taxol. These compounds have inhibitory concentration $50\left(\mathrm{IC}_{50}\right)$ values ranging from 0.1 to $4 \mu \mathrm{g} / \mathrm{ml}$ [91]. Some plants extracts have been reported to lack cytotoxic effects $\left(\mathrm{IC}_{50}>250 \mu \mathrm{g} / \mathrm{ml}\right)$ in nontumorigenic cells. These include the ethanol extract of Phoradendron serotinum leaves tested on peripheral blood mononuclear cells [91], the aqueous extract of Cnidoscolus chayamansa leaves on baby hamster kidney (BHK) cells [92], and the aqueous extract of Enterolobium cyclocarpum bark assayed on 3T3 murine preadipocytes [82]. Additionally, the ethanol extract of Equisetum hyemale aerial parts evaluated on rabbit corneal fibroblasts (SIRC) [93], the methanol extract of Enterolobium cyclocarpum leaves evaluated on Vero cells (obtained from kidney epithelial cells extracted from the African green monkey (Cercopithecus aethiops) [88], and the diterpene ent-kaur-16-en-19-oic acid, obtained from Annona cherimola, tested on rat embryo primary striatal cultures [94]. On the other hand, the hydroalcoholic extract of Hura crepitans leaves had an $\mathrm{IC}_{50}=107.7 \mu \mathrm{g} / \mathrm{ml}$ in lung fibroblasts [95].

4.1.2. Mutagenicity and Genotoxicity. Regarding mutagenicity, parthenin, isolated from Parthenium hysterophorus, 
lacked mutagenicity $(0.19$ to $19 \mu \mathrm{M})$ but showed chromosomal aberrations at concentrations of $10-60 \mu \mathrm{M}$ in blood lymphocytes [96]. These results suggested genotoxic effects of parthenin. A methanol extract of Indigofera suffruticosa aerial parts (1.25-7.5 mg/plate) showed mutagenic activity in a Salmonella microsome assay [97]. The acetone extract of Heliopsis longipes roots $(10-80 \mu \mathrm{g} /$ Petri dish) and its active compound affinin (6.25-50 $\mu \mathrm{g} /$ Petri dish) were not mutagenic, as evaluated by the Ames test [98]. Lobeline (5-10 mg/kg i.p.), an alkaloid isolated from Lobelia inflata, had no genotoxic or mutagenic effects in the comet assay, the micronucleus test in bone marrow, or the Salmonella/ microsome mutagenic assay [99].

For genotoxicity, the ethyl acetate/n-hexane extract of Zinnia peruviana aerial parts tested using 5 and $20 \mathrm{mg} / \mathrm{ml}$ extracts showed genotoxic effects in PBMC compared to the positive control of copper sulfate (1\%) [100]. A butanol fraction of Urera baccifera roots at a $1.8 \mathrm{mg} / \mathrm{g}$ concentration of oxalic acid decreased leukocyte number significantly and increased cell death and DNA damage in primary cultures of leukocytes in comparison to the control treatment [101]. The methanolic extract of Psittacanthus calyculatus aerial parts (200 and $400 \mathrm{mg} / \mathrm{kg}$ i.p.) did not induce chromosomal damage in peripheral blood erythrocytes obtained from mice after $72 \mathrm{~h}$ of exposure [102]. An ethanol extract of Heliopsis longipes roots (3-100 mg/kg p.o.) did not produce genotoxic or cytotoxic effects on peripheral blood mononuclear cells obtained from mice $24-96 \mathrm{~h}$ after administration [103]. Parthenin, isolated from Parthenium hysterophorus, showed genotoxic effects at $4-31 \mathrm{mg} / \mathrm{kg}$ i.p. in micronuclei in mouse peripheral blood after 48 and $72 \mathrm{~h}$ of treatment [96].

\subsection{In Vivo Acute Studies}

4.2.1. Lethal Dose $50\left(L D_{50}\right)$. The guideline 423 of the Organization for Economic Cooperation and Development (OECD) establishes that substances with an $\mathrm{LD}_{50}<5 \mathrm{mg} / \mathrm{kg}$ are highly toxic, whereas $\mathrm{LD}_{50}$ values from 5 to $50 \mathrm{mg} / \mathrm{kg}$ are very toxic, $\mathrm{LD}_{50}$ values from 50 to $300 \mathrm{mg} / \mathrm{kg}$ are toxic, $\mathrm{LD}_{50}$ values from 300 to $2000 \mathrm{mg} / \mathrm{kg}$ are dangerous, and $\mathrm{LD}_{50}$ values higher than $2000 \mathrm{mg} / \mathrm{kg}$ are not dangerous [104].

Some plant extracts showed $\mathrm{LD}_{50}>2000 \mathrm{mg} / \mathrm{kg}$ p.o. in mice: ethanol extracts of leaves of Casimiroa edulis [105] and Cnidoscolus chayamansa [106], ethanol extracts of aerial parts of Moussonia deppeana [107], Equisetum hyemale [93], and Ruta chalepensis [108], as well as methanol extracts of leaves of Chenopodium ambrosioides [109] and Rauvolfia tetraphylla [110]. The same pattern was also shown in aqueous extract of Cuphea aequipetala aerial parts [111], ethanol extract of Plumeria rubra flowers [112], aqueous extract of Larrea divaricata leaves [113], ethanol extract of Caesalpinia pulcherrima leaves and bark $[114,115]$. aqueous extract of Euphorbia prostrata whole plant [116], aqueous-methanol extract of Ceiba pentandra leaves [117], petroleum ether, chloroform, and methanol extracts of Gelsemium sempervirens roots [118], acetone extract of Capsicum annum fruits [119], and aqueous and ethanol extract of Scoparia dulcis leaves and whole plant $[120,121]$.
The following extracts have shown $\mathrm{LD}_{50}>2000 \mathrm{mg} / \mathrm{kg}$ p.o. in rats: aqueous extract of Pouteria sapota seeds [122], methanol extract of Martynia annua leaves [123], ethanol extract of Flourensia cernua leaves [124], aqueous extract of Enterolobium cyclocarpum bark [82], ethanol and aqueous extract C. pulcherrima aerial parts [125], aqueous extract of Passiflora edulis leaves [126], hydroalcoholic extract of Magnolia grandiflora seeds [127], and ethanol extract of Crescentia cujete fruits [128]. The same pattern was also shown in methanol extracts of leaves of Amaranthus spinosus [129], and Rauvolfia tetraphylla [130], chloroform-methanol extract of Cnidoscolus chayamansa leaves [131], aqueous extract of $R$. humilis fruits [132], a chloroform fraction from an ethanol extract of Tagetes erecta flowers [133], aqueous extract of Karwinskia humboldtiana seeds [134], and hydroalcoholic extract of Senna occidentalis aerial parts [135], as well as lutein and lutein ester, obtained from Tagetes erecta [136], and ethanol extract of Jatropha gossypiifolia aerial parts [137], and aqueous extract of Caladium bicolor [138].

Other plant extracts showed $\mathrm{LD}_{50}>2000 \mathrm{mg} / \mathrm{kg}$ i.p. in mice: hexane extract of Tilia mexicana inflorescences [139], aqueous extract of Tagetes lucida aerial parts [140], ethanol extract of Mirabilis jalapa aerial parts [141], and aqueous extract of Urera baccifera leaves [142].

Some plant extracts and plant compounds had $\mathrm{LD}_{50}$ values from 300 to $2000 \mathrm{mg} / \mathrm{kg}$, which is considered dangerous [104]. These plant extracts were intraperitoneally administered to mice: the ethanol extract of Tagetes lucida aerial parts $\left(\mathrm{LD}_{50}=970 \mathrm{mg} / \mathrm{kg}\right)$ [140], the aqueous extract of Caladium bicolor leaves $\left(\mathrm{LD}_{50}=1778.28 \mathrm{mg} / \mathrm{kg}\right)$ [138], and the ethanol extract of Tagetes lucida aerial parts $\left(\mathrm{LD}_{50}=970 \mathrm{mg} / \mathrm{kg}\right.$ i.p.) [140]. On the other hand, the ethanol extract of Phoradendron serotinum leaves had an $\mathrm{LD}_{50}=375 \mathrm{mg} / \mathrm{kg}$ p.o. in mice [143], and sanguinarine, an alkaloid isolated from Sanguinaria canadensis, had an $\mathrm{LD}_{50}=1658 \mathrm{mg} / \mathrm{kg}$ p.o. in rats [144]. Methanol extracts of Tilia mexicana inflorescences had $\mathrm{LD}_{50}$ values of $375 \mathrm{mg} / \mathrm{kg}$ i.p. in mice [139].

Other plant extracts and plant compounds had $\mathrm{LD}_{50}$ values varying from 50 to $300 \mathrm{mg} / \mathrm{kg}$, which is considered toxic [104]. Ethanol extract of Phoradendron serotinum leaves had an $\mathrm{LD}_{50}=125 \mathrm{mg} / \mathrm{kg}$ i.p. in mice, [143], whereas capsaicin, the main active principle of Capsicum annum, had an $\mathrm{LD}_{50}=$ $190 \mathrm{mg} / \mathrm{kg}$ p.o. [145]. The acetone extract of Heliopsis longipes roots had an $\mathrm{LD}_{50}=62.14 \mathrm{mg} / \mathrm{kg}$ p.o. in mice, whereas its active compound affinin had an $\mathrm{LD}_{50}=113.13 \mathrm{mg} / \mathrm{kg}$ p.o. in mice [98]. The ethanol extract of Heliopsis longipes roots had an $\mathrm{LD}_{50}=288 \mathrm{mg} / \mathrm{kg}$ p.o. in mice [103].

The following plant extracts and compounds can be considered very toxic $(5-50 \mathrm{mg} / \mathrm{kg}$ ) [104]: the free alkaloid fraction in hexane and methanol extracts from Erythrina americana seeds $\left(\mathrm{LD}_{50}=38.54\right.$ to $40.37 \mathrm{mg} / \mathrm{kg}$ i.p. $)$ in mice [146], Jatropha curcas oil $\left(\mathrm{LD}_{50}=23.34 \mathrm{mg} / \mathrm{kg}\right.$ p.o. $)$ in mice [147], and $\alpha$-solamargine, isolated from Solanum americanum, with an $\mathrm{LD}_{50}=42 \pm 2 \mathrm{mg} / \mathrm{kg}$ i.p. in rats [148]. The alkaloid $\mathrm{N}$ methylisocorydinium, obtained from Magnolia grandiflora trunk wood, had an $\mathrm{LD}_{50}=10 \mathrm{mg} / \mathrm{kg}$ i.p. in mice [149] and $\gamma$ coniceine, isolated from Conium maculatum, had an $\mathrm{LD}_{50}=$ $12 \mathrm{mg} / \mathrm{kg}$ p.o in mice [150]. Parthenin, the toxic compound of Parthenium hysterophorus, had an $\mathrm{LD}_{50}=42 \mathrm{mg} / \mathrm{kg}$ i.p. in rats 
[151]. Capsaicin had an $\mathrm{LD}_{50}=8 \mathrm{mg} / \mathrm{kg}$ i.p. and $7.80 \mathrm{mg} / \mathrm{kg}$ i.m in mice [152]. Sanguinarine, an alkaloid isolated from Sanguinaria canadensis, was toxic at $29 \mathrm{mg} / \mathrm{kg}$ i.v. in rats [144].

The following plant compounds had $\mathrm{LD}_{50}$ values < $5 \mathrm{mg} / \mathrm{kg}$, which is considered highly toxic [104]. Capsaicin had an $\mathrm{LD}_{50}=0.56 \mathrm{mg} / \mathrm{kg}$ i.v. [152].

4.2.2. Biochemical and Hematological Parameters. Treatment with plant extracts in short-term studies have effects on biochemical and hematological parameters, as well as the levels of the hepatic enzymes alanine aminotransferase (ALT), aspartate aminotransferase (AST), and alkaline phosphatase (ALP). An aqueous extract of Larrea divaricata aerial parts $(0.5-200 \mathrm{mg} / \mathrm{kg}$ i.p.) did not affect the levels of ALT in mice after 2 days [153]. Aqueous extract of Karwinskia humboldtiana fruits (1250 mg/kg p.o.) administered to rats for 3 days increased the levels of hepatic enzymes compared to the untreated group [154]. An aqueous extract of Passiflora edulis $(30 \mathrm{mg} / \mathrm{kg}$ p.o.) did not affect motor coordination in mice or change the biochemical measurements in serum after 4 days [155]. $\alpha$-Solamargine (15-35 mg/kg i.p.) did not affect hematological parameters or the levels of hepatic enzymes in rats after 5 days [148], whereas an aqueous extract of Karwinskia humboldtiana fruit $(5000 \mathrm{mg} / \mathrm{kg}$ p.o.) in rats for 5 days induced weight loss (15\%) in rats, as well as toxicity in the pancreas [156]. An aqueous extract of Passiflora edulis leaves (100-400 mg/kg p.o.) did not affect organ body weight or hematological parameters but decreased the levels of ALT in rats after 7 days of treatment at all doses [126]. A methanol extract of $R$. tetraphylla leaves (1000 mg/kg p.o.) decreased body weight change and food consumption and increased total bilirubin in rats after 7 days [157]. An aqueous extract of K. humboldtiana (1000-2000 mg/kg p.o.) administered for 7 days in rats induced alterations in membrane fluidity and ATPase activity in liver submitochondrial particles [158]. An ethanol extract of Euphorbia hirta leaves $(60.4-483 \mathrm{mg} / \mathrm{kg}$ i.p.) [159] and a chloroform fraction from an ethanol extract of Tagetes erecta flowers (200-400 mg/kg p.o.) [133] did not affect hematological or biochemical parameters in rats after 14 days. An aqueous extract of Euphorbia hirta whole plant administered at a single dose of $2000 \mathrm{mg} / \mathrm{kg}$ p.o. significantly decreased the levels of ALP and ALT after 14 days in broiler chickens [160]. Lobeline (5-10 mg/kg i.p.) did not affect the levels of AST, ALT, ALP, and LDH after 4 days of exposure [99].

4.2.3. Toxicity to Reproduction and Pregnancy. $\alpha$-Solamargine (15-35 mg/kg i.p.) did not affect the number of spermatozoa or the weight of the testicles and epididymis of male rats after $24 \mathrm{~h}$ of treatment [148]. Jervine (70-300 mg/kg p.o.), a steroidal alkaloid found in Veratrum californicum, administered on days $8-10$ of gestation induced malformations in the offspring, including isolated cleft palate, mandibular micrognathia, and limb malformations in C57BL/6J and A/J mice [161]. The administration of an aqueous extract of Ruta chalepensis leaves (10 mg/kg p.o.) to pregnant rats from day 9 to day 17 of gestation decreased the uterine weight, the number of live fetuses, and the fetal weight.
The number of fetal resorptions was also increased, and the fetuses showed skeletal malformations [162]. Additionally, an aqueous extract of $R$. chalepensis leaves $(0.8$ and $1.6 \mathrm{~g} / \mathrm{kg}$ p.o.) administered to mice from day 1 to day 14 post coitum caused perinatal changes in mice such as righting reflex, cliff avoidance, and swimming ability, among others [163].

4.2.4. Dermal Tests. An aqueous extract of Pouteria sapota seeds lacked dermal irritation in rabbits and showed mild reversible eye irritation in rabbits [122]. Jatropha multifida sap did not induce skin lesions in rats after 14 days of treatment [164]. A diethyl ether extract of Jatropha multifida showed the presence of 16-hydroxyphorbol. This compound showed an irritant dose $50\left(\mathrm{ID}_{50}\right)$ of $0.05 \mu \mathrm{g} /$ ear [165].

\subsection{In Vivo Subacute and Chronic Studies}

4.3.1. Biochemical and Hematological Parameters. Some plant extracts and their active compounds have been tested for their effects on biochemical and hematological parameters in rodents for at least 18 days of exposure. A histological study has also been included in some reports. A hydroalcoholic extract of Senna occidentalis aerial parts $(100-2500 \mathrm{mg} / \mathrm{kg}$ p.o.) [135] and a hydroalcoholic extract of Sapindus saponaria leaves (44.76 mg/kg p.o.) and fruits (45.0 mg/kg p.o.) [166] did not change the biochemical profile or hematological parameters or alter body weight and organ weight for 30 days in rats. An ethanol extract of the pod of Plumeria rubra (50-200 mg/kg p.o) [167] and an aqueous-methanol extract of Ceiba pentandra leaves (250 and $500 \mathrm{mg} / \mathrm{kg}$ p.o.) [117] did not alter hematological or biochemical parameters in rats and mice, respectively, after 21 days [167]. A chloroform-methanol extract of Cnidoscolus chayamansa leaves (1000 mg/kg p.o.) [131] and an ethanol extract of Moussonia deppeana aerial parts (1000 mg/kg p.o.) [107] did not affect biochemical or hematological parameters in mice after 28 days of daily administration. In addition, histological examinations of the spleen, kidney, and liver showed no abnormalities. Capsaicin (5-100 mg/kg p.o.) [168], obtained from Capsicum annum, and lutein and lutein ester (4-400 mg/kg p.o.) [136], obtained from Tagetes erecta, did not affect hematological or biochemical parameters, growth, food consumption, or body weight in mice and rats, respectively, after 28 days. An aqueous extract of Rivina humilis fruits $(2500$ and $5000 \mathrm{mg} / \mathrm{kg}$ p.o.) administered daily for 35 days showed no changes in the hematological profile or in the relative organ weight, whereas the same extract administered daily for 90 days at $0.5-2 \mathrm{~g} / 100 \mathrm{~g}$ in a powdered diet did not affect hematological parameters, biochemical determinations, or the levels of hepatic enzymes [132].

In contrast, some plant extracts have altered biochemical and/or hematological parameters. An aqueous extract of Abrus precatorius leaves (400-1600 mg/kg p.o.) was administered to rats for 18 days. Only the highest dose $(1600 \mathrm{mg} / \mathrm{kg}$ p.o.) decreased levels of hematological parameters and increased the levels of hepatic enzymes [169]. An aqueous extract of Scoparia dulcis leaves (250-500 mg/kg p.o.) showed mild vascular and portal congestion in the heart and the 
liver, respectively, of rats treated daily with this extract for 30 days. Nevertheless, there were effects in the lungs and testis [120]. A methanol extract of Rauvolfia tetraphylla leaves did not affect hematological parameters. However, a significant decrease in the total bilirubin and glucose levels was observed in the mice treated at 100 and $300 \mathrm{mg} / \mathrm{kg}$, with a significant increase in triglycerides at doses of $10-300 \mathrm{mg} / \mathrm{kg}$ after 28 days in mice [130]. An ethanol extract of the aerial parts from Jatropha gossypifolia $(135 \mathrm{mg} / \mathrm{kg}$ p.o. or higher doses) reduced the activity in the central nervous system and showed hepatotoxicity, pulmonary damage, and digestive disturbances in rats over 13 weeks of treatment [170]. The lethality was $46.6 \%$ and $13.3 \%$ among male and female rats under the highest tested dose $(405 \mathrm{mg} / \mathrm{kg})$, respectively [170].

4.3.2. Toxicity during Reproduction and Pregnancy. Yao et al. [171] reported that an aqueous extract of Hydrastis canadensis $(1.86 \mathrm{~g} / \mathrm{kg}$ p.o.) containing $9.6 \mathrm{mg} / \mathrm{ml}$ of berberine and $8.4 \mathrm{mg} / \mathrm{ml}$ of hydrastine did not affect fetal development in pregnant rats over 20 days of treatment. A Prosopis juliflora seedcase added at $70 \%$ to the diet of pregnant rats resulted to be teratogenic (13-fold) compared to the untreated group [172]. Aqueous and ethanol extracts of Plumeria rubra pods (200 mg/kg p.o.) had $51 \%$ and $100 \%$ abortifacient activity, respectively, in female albino rats from day 11 to day 15 of pregnancy [173]. The hydroalcoholic extract of Lantana camara leaves (1000-7000 mg/kg p.o.) administered during premating, mating, pregnancy, and lactation (56 days in total) in rats did not affect mating, pregnancy, delivery, and live birth. Nevertheless, the two highest doses tested (3000 and $7000 \mathrm{mg} / \mathrm{kg}$ p.o.) produced an increase in the resorption rate and parallel increases in the postimplantation loss index, as well as embryotoxicity characterized by skeletal abnormalities [174].

4.3.3. Carcinogenicity. Only one plant extract has been tested for its carcinogenic effects. Rats (treated with doses ranging $136-1175 \mathrm{mg} / \mathrm{kg}$ p.o.) and mice (treated with doses ranging $375-3275 \mathrm{mg} / \mathrm{kg}$ ) received an aqueous extract of Hydrastis canadensis root for 2 years (106 weeks). At the end of the treatment, the doses of $1175 \mathrm{mg} / \mathrm{kg}$ in rats and the doses varying from 1120 to $3275 \mathrm{mg} / \mathrm{kg}$ in mice showed hepatocarcinoma [175].

4.4. Clinical Cases. The toxicity of sixteen species plants has been reported in clinical cases. Fourteen of the sixteen plants are enlisted in Table 2. The other two plants are described in Section 4.4.1. The Naranjo algorithm [176], which consists of 10 questions that address the factors considered to determine the causal relationship in case reports, was used to assess causality. A score is obtained (maximum 13) and the results are classified as doubtful or unlikely (0), possible (from 1 to 4), probable (from 5 to 8 ), and clear or definite (socre $>9$ ). The event must be definitive from a pharmacological or phenomenological point of view, using, if necessary, a conclusive procedure of reexposure [177].
Those cases that report hepatic damage were also evaluated using the method proposed by the Council for International Organizations of Medical Sciences/Roussel Uclaf Causality Assessment Method (CIOMS/RUCAM) [178], which is an organospecific instrument designed for the assessment of hepatotoxicity. This method evaluates the temporal relationship between the consumption of a substance (drug or natural remedy) and the appearance of hepatic damage, the absence or presence of risk factors, the exclusion of alternative causes of liver injury, among others. The sum of the scores leads to a final score between -8 and 14 points, which results in the following categories: highly probable or definite, probable, possible, or excluded. The amount of information of each clinical case considered for this review was classified as enough (number of criteria: 5-6), regular (number of criteria: 3-4), and poor (number of criteria: 1-2). The following criteria were used to evaluate the amount of information: (1) clear information regarding the intake and time elapsed for the onset of symptoms, (2) information of the dose ingested, (3) explanation and clinical management of the intoxication, (4) information for the exclusion of other causes that might induce the toxic effect, (5) information of the withdrawal of the plant substance, and (6) time of recovery from the toxicity or death of the patient.

The toxicity presented in clinical cases was mainly due to the accidental consumption of toxic medicinal plants, especially by children. In all the cases, the toxic effects occurred after the administration of the plant. The symptoms of toxicity were confirmed using objective evidence. None of the reports provided information about the presence of similar toxic effects compared to a previous experience. Improvement of symptoms occurred in some cases (i.e., [58, $62-64,69,71,72])$. The information about the number of ingestion with the plant is only reported in some cases (i.e., $[43,57,59,60,65,67,70])$.

4.4.1. Case Series. Krenzelok et el. [179] gathered information about Euphorbia pulcherrima exposure during an 8-year period in the United States of America. The results showed that children accounted for $93.3 \%$ of cases of exposure, which were accidental (98.9\% of cases) and by ingestion (94.5\% of cases). No deaths were reported. However, this study did not report the symptomatology. The toxicity of Cimicifuga racemosa has been extensively studied. The reviews of Borrelli and Ernst [180] and Teschke et al. [181] can be consulted for more information regarding the adverse effects of Cimicifuga racemosa in other clinical cases. The prevalence of allergy to Myroxylon pereirae resin has been reported in many countries, ranging from 5.4 to $11.8 \%$ (i.e., [ $49,182-185]$ ). From a total of 27815 patients recorded over 5 years in Croatia, $8.4 \%$ were positive to contact dermatitis upon exposure to Myroxylon pereirae bark [186]. In another case, the prevalence of toxicity by medicinal plants was also reported. Jatropha curcas, Andira inermis, and Canella winterana were the third, the fourth, and the fifth most cited plant species, respectively, associated with cases of toxicity in Cuba from 1998-2007 [36]. Eddleston et al. [187] reported 351 patients with a history of T. peruviana consumption for 2 years. No deaths were reported. 


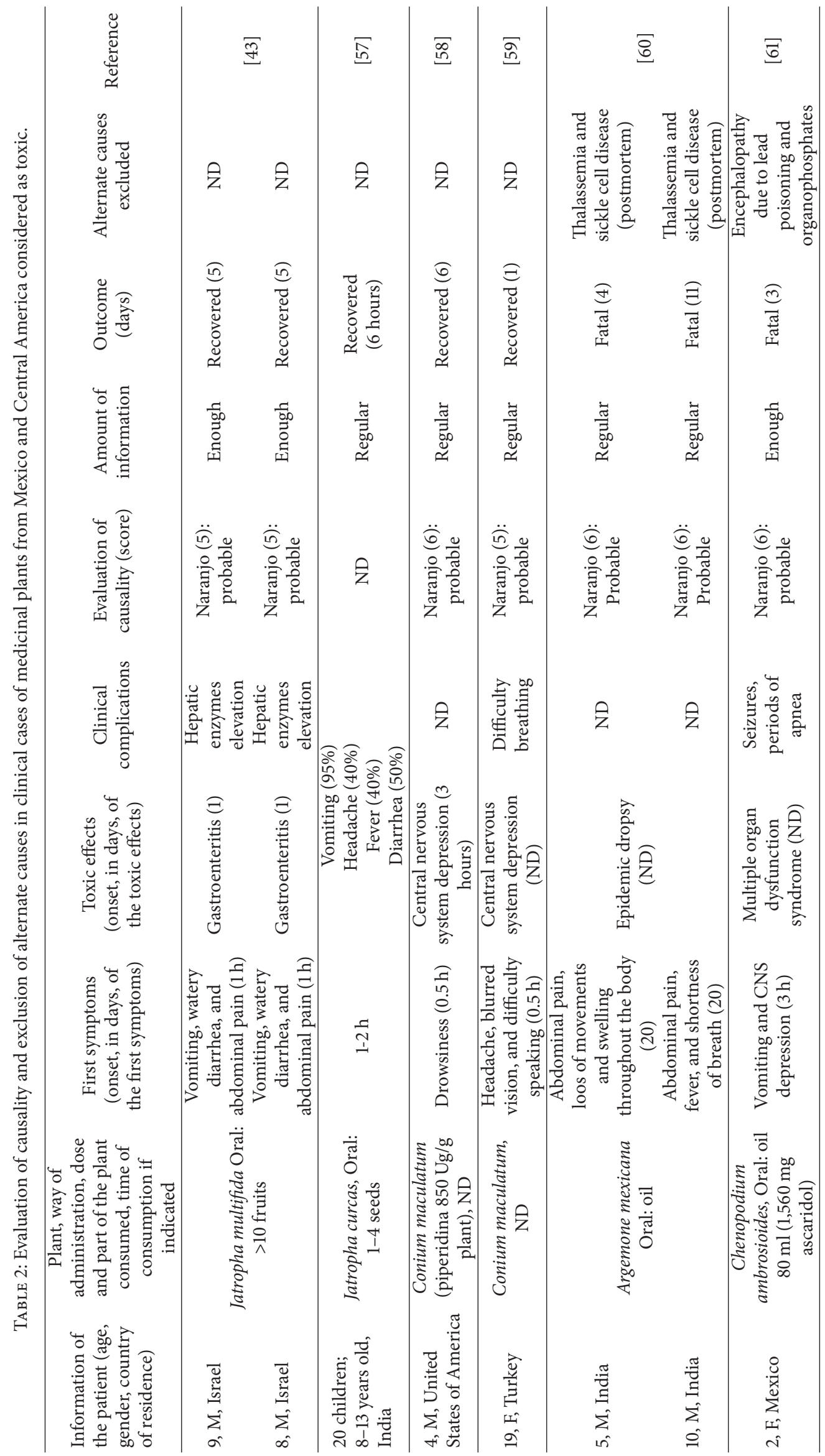




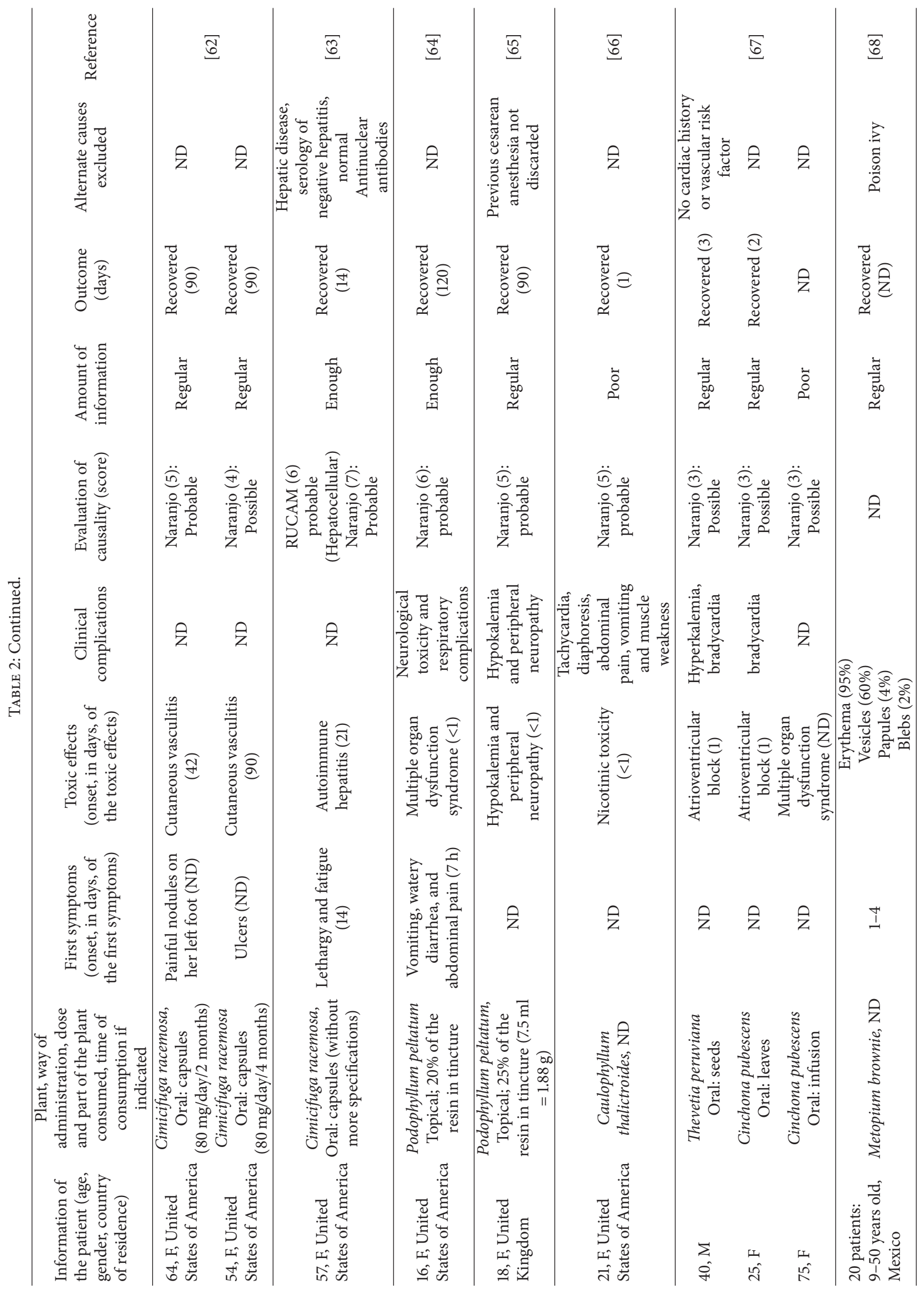




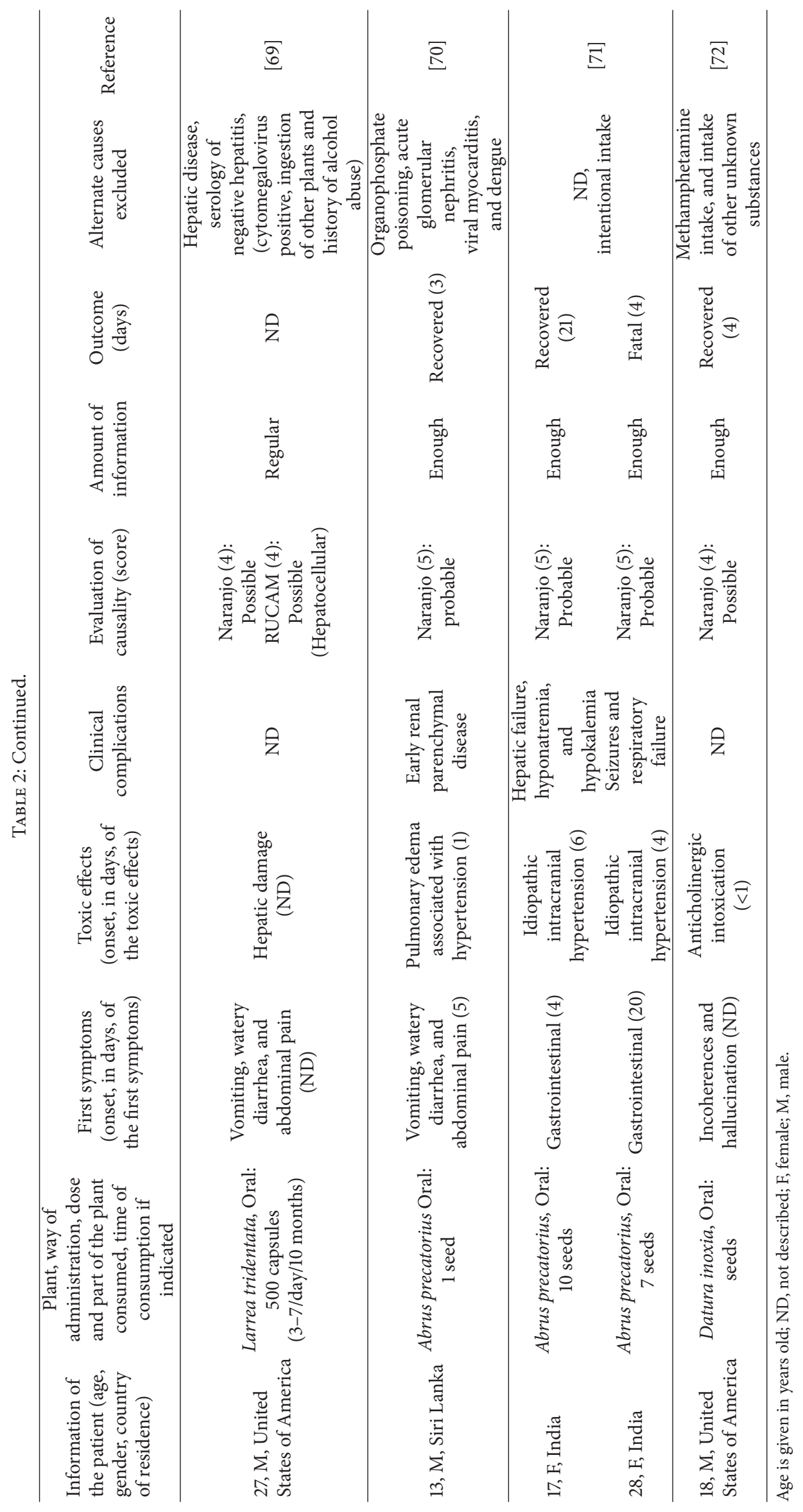




\section{General Considerations}

The identification of the compounds responsible for the toxicity has been reported only in some cases. Urushiol might be the compound responsible for the dermatitis reactions to Metopium brownei [188], whereas sanguinarine is the compound associated with the toxicity of Argemone mexicana. Eddleston et al. [189] reported six fatalities in patients who ingested between 1 and 10 seeds of T. peruviana. These fatalities occurred due to high concentrations of cardiac glycosides (neriifolin, thevetin $\mathrm{A}$, thevetin $\mathrm{B}$, and oleandrin) in seeds. Three toxins (T-544, T-514, and T-496) have been reported in Karwinskia humboldtiana [190]. Manihot esculenta, an important dietary staple, is toxic because of the presence of cyanogenic compounds. Linamarin, the predominant cyanogenic glycoside in Manihot esculenta, can be accumulated in a range of concentrations between 100 and $500 \mathrm{mg} / \mathrm{kg}$ in roots and leaves. The content of HCN in Manihot esculenta has been reported $0.1-1 \mathrm{mg} / \mathrm{g}$ fresh weight in the leaves [191]. Several intoxications have been described in humans. The clinical pattern consists of neuropathy and hyperthyroidism [192].

The mechanism of toxicity is also unknown in many cases. The mechanism of toxicity of Argemone mexicana oil might be explained by the inhibitory effects of sanguinarine on $\mathrm{Na}+\mathrm{K}+\mathrm{ATPase}$, induction of cell membrane damage by reactive oxygen species and lipid peroxidation, and inhibition of DNA polymerase activity, among other effects [193]. Larrea tridentata and nordihydroguaiaretic acid, its active compound, generate acute hepatotoxicity by the inhibition of cyclooxygenase and cytochrome P-450 [194].

Special attention should be given in medicinal plants such as Argemone mexicana, Chenopodium ambrosioides, and Thevetia peruviana. Effects in humans have been reported due the consumption of these medicinal plants. Other plant species, including Abrus precatorius, Capsicum annum, Conium maculatum, Erythrina Americana, Heliopsis longipes, Hydrastis canadensis, Jatropha curcas, Jatropha gossypifolia, Karwinskia humboldtiana, Larrea tridentata, Magnolia grandiflora, Parthenium hysterophorus, Phoradendron serotinum, Plumeria rubra, Prosopis juliflora, Ruta chalepensis, Sanguinaria canadensis, Solanum americanum, and Veratrum californicum, have shown effects considered highly toxic, including hepatotoxicity, teratogenic, and cardiotoxicity, or with high toxicity in acute studies. Therefore, a total of 22 plants of 216 cited in this review should be extensively studied in terms of their toxicity. Regarding the hepatotoxicity induced by medicinal plants, Valdivia-Correa [39] reported 15 medicinal plants commonly used in Mexican traditional medicine that induce hepatotoxicity. Five (Equisetum hyemale, Tilia mexicana, Passiflora edulis, and Scoparia dulcis) of these fifteen medicinal are considered as toxic, according to our bibliographic research. The induction of hepatotoxicity induced by herbal products represents a serious problem in Mexico since the symptoms and signs might be confused with other diseases, and the diagnosis can be incorrect [39].

Some aspects that influence the toxicity of medicinal plants reported in this study are: (a) time of exposure, (b) misidentification of medicinal plants, and (c) adulteration of medicinal plants. Most of the acute symptoms reported in this review appear in the first $24 \mathrm{~h}$ after exposure. Nevertheless, more studies, including subacute and chronic assays, as well as the quantitation of hepatic enzymes, should be performed. In other cases, such as the intoxication of Crotalaria sagittalis, the toxic symptoms appear 2 to 6 months after the exposure [4]. However, chronic poisoning induced by medicinal plants is not easily detected since the symptoms are multiple and variable and a diagnosis cannot be made. Many poisonings caused by medicinal plants are classified as of unknown origin because most of the patients deny the consumption of herbal products. For instance, the clinical picture of intoxication with Karwinskia humboldtiana might be confused with poliomyelitis [190]. In addition, in most of the cases, the plants are not taxonomically identified [36]. The misidentification of medicinal plants represents a serious problem for human health. The adulteration of medicinal plants sold as food products should be considered as a risk of intoxication by medicinal plants.

Another aspect to consider for further studies is the evaluation of mixtures of medicinal plants and the combination of medicinal plants with allopathic medications. It is thought that the combination of medicinal plants might result in higher beneficial effects compared to those found with single preparations. Nevertheless, it might be the case that two toxic plants are combined and their toxic effects might result in a synergistic action. The self-medication of drugs along with the consumption of medicinal plants is a common practice among patients with chronic diseases [195], which can be considered as an alternative cause of intoxication. In the clinical record, it is not indicated whether the patient consumes medicinal plants. The interaction of herbal extracts and drugs remains to be studied. There are few documented cases that report the toxicity of the combination of plant extracts and drugs. For instance, the combination of Picrasma excelsa coumarins are reported to potentiate the activity of warfarin [196]. The toxicity of mixtures of medicinal plants and the combination of medicinal plants with allopathic medication requires further investigation.

\section{Conclusions}

There is limited information about the toxicity of medicinal plants used in Mexico, Central America, and the Caribbean. The molecular mechanisms by which medicinal plants induce toxic effects should also be addressed. In many cases, intoxication by medicinal plants might be confused with other diseases. The detection of intoxication with medicinal plants could be difficult because the symptoms might be confused with other diseases.

The prevention of poisoning in humans can be avoided if the chemical composition of medicinal plants is known.

\section{Conflicts of Interest}

The authors declare that there are no conflicts of interest. 


\section{References}

[1] UICN, OMS, and WWF, "Guidelines on the conservation of medicinal plants World Health Organization (OMS)," in Unión Internacional para la Conservación de la Naturaleza (UICN) and World Wild life Fund (WWF), Gland, Switzerland, 1993.

[2] G. A. Taddei-Bringas, M. A. Santillana-Macedo, J. A. RomeroCancio, and M. B. Romero-Téllez, "Acceptance and use of therapeutic medical plants in family medical care," Salud Pública de México, vol. 41, no. 3, pp. 216-220, 1999.

[3] Botanical and plant derived drugs, "Global markets. BCC Research Report BIO022G," http://www.bccresearch.com/marketresearch/biotechnology/botanical-plant-derived-drugs-reportbio022g.html.

[4] A. Aguilar-Contreras and C. Zollas, Plantas tóxicas de México. Instituto Mexicano del Seguro Social, Mexico city, Mexico, 1982.

[5] M. H. Royo-Márquez and A. Melgoza-Castillo, "Listado florístico del campo experimental la campana y usos de su flora," Técnica Pecuaria Mexicana, vol. 39, no. 2, pp. 105-125, 2001.

[6] M. E. Mitre and N. Camacho, Plantas Medicinales de la Cuenca Hidrográfica del Canal de Panamá, vol. 6, Editora Sibauste, Panamá, Panama, 2013.

[7] S. Castañeda-Díaz, Uso de la vegetación forestal fanerogamica de San Miguel Pipillola, Tlaxcala, México [Bachelor thesis], Universidad Autónoma Chapingo, Texcoco, Estado de México, México, 2013.

[8] J. S. Flores, G. C. O. Canto-Aviles, and A. G. Flores-Serrano, "Plantas de la flora yucatense que provocan toxicidad en el humano," Revista Biomedica, vol. 12, no. 2, pp. 86-96, 2001.

[9] L. C. Navarro-Pérez and S. Avendaño-Reyes, "Flora útil del municipio de Astancinga, Veracruz, Mexico," Polibotanica, vol. 14, pp. 67-84, 2002.

[10] C. Gutiérrez-Báez, Plantas útiles de Chiconquiaco, Veracruz, vol. 19, Universidad Veracruzana, La Ciencia y el Hombre, 1995.

[11] L. S. Nelson and M. J. Shih, Handbook of poisonous and injurious plants, New York Botanical Garden, Springer-Verlag, New York, NY, USA, 2007.

[12] A. M. Fernández-Brewer, V. Juárez-Jaimes, and L. CortésZárraga, "Usos de las especies del género Asclepias L. (Apocynaceae, aclepiadoideae), información del herbario nacional de México, MEXU," Polibotanica, vol. 25, pp. 155-171, 2008.

[13] O. González-Costilla, Estudio etnobotanico del municipio de Matehuala, San Luis Potosí, México, Universidad Autónoma de [M.sc. thesis], Universidad Autónoma de Nuevo León, México, 1991.

[14] G. García-Regalado, Plantas medicinales de Aguascalientes, Universidad Autónoma de Aguascalientes, Aguascalientes, Aguascalientes., México, 2014.

[15] M. Martínez, Las plantas medicinales de México, Editorial Botas, México city, México, 1996.

[16] B. Juscafresa, "Guía de la flora medicinal: tóxica, aromática y condimenticia," in Editorial Aedos, vol. 851, p. 542, Barcelona, España, 1995.

[17] Y. A. González, M. Peña, J. Pérez Agreda, and M. Díaz, "Intoxicación por la administración de tabletas de Thevetia peruvianacomo tratamiento para bajar de peso: presentación de un caso," Revista de Toxicología, vol. 20, no. 3, pp. 221-223, 2003.

[18] F. Lagunes-Gutierrez, Vademecum de plantas medicinales del municipio de puente nacional, Veracruz, Universidad Veracruzana, México, 2013.
[19] A. DerMarderosian and J. A. Beutler, "The Review of Natural Products: the most complete source of natural product information," in editorial Facts and Comparisons, p. 1672, St Louis, United States of America, editorial Facts and Comparisons, 2002.

[20] D. W. Nellis, "Poisonous plants and animals of Florida and the Caribbean," in USA, p. 321, Pineapple Press, Sarasota, 1997.

[21] L. González-Chévez, P. Hersch-Martinez, and A. Juárez-Miranda, Plantas medicinales de Copalilloy Temalac, Guerrero, Instituto Nacional de Antropología e Historia, Consejo Nacional de Ciencia y Tecnología, Mexico city, Mexico, 2000.

[22] P. Giovannini and M. Heinrich, "Xki yoma' (our medicine) and xki tienda (patent medicine)-Interface between traditional and modern medicine among the Mazatecs of Oaxaca, Mexico," Journal of Ethnopharmacology, vol. 121, no. 3, pp. 383-399, 2009.

[23] S. Blair-Trujillo and B. Madrigal, "Plantas antimalaricas de Tucumaco, costa pacífica Colombiana," in Editorial Universidad de Antioquia, p. 348, Medellin, Colombia, 2005.

[24] P. J. Salinas, "Plantas tóxicas comunes en el estado de Merida, Venezuela. Segunda parte. Adoxaceae, Asteraceae, Caesalpinaceae, Chenopodiaceae, Combretaceae, Cruciferaceae, Cycadaceae, Ericaceae, Euphorbiaceae, Fabiaceae, Lamiaceae, Malvaceae, Moraceae, Myrtaceae, Papaveraceaea," Revista.Facultad de Medicina, vol. 21, no. 1, pp. 26-46, 2012.

[25] L. O. Loreno-Medina, J. M. Rodríguez-Chávez, and M. G. Ramos-Espinosa, "Aprovechamiento de recursos vegetales en una localidad de la reserva de la biosfera mariposa monarca, Michoacán, México," Etnobiología, vol. 2, no. 1, pp. 33-60, 2002.

[26] J. Adame and H. Adame, "Plantas curativas del noreste mexicano," in Ediciones Castillo, p. 347, Monterrey Nuevo Leon, México, 2000.

[27] J. González-Rodrigo and J. González-Rodrigo, Editorial Universidad Iberoamericana, vol. 3, México City, México, 1993.

[28] J. C. Ríos, E. París, and G. Repetto, "Intoxicaciones por plantas medicinales," in Toxicología Alimentaria, A. M. Cameán and M. Repetto, Eds., pp. 212-222, Madrid, Spain, 2012.

[29] G. Gutiérrez, M. E. Siqueiros-Delgado, H. E. RodríguezChávez, M. De la, and E. Cerda-Lemus, "Comisión Nacional para el Conocimiento y Uso de la Biodiversidad (CONABIO)/ Instituto de Ecología del Estado de Guanajuato," in en Guanajuato: Estudio de Estado, A. Cruz-Angón, E. D. Melgarejo, A. V. Contreras-Ruiz Esparza, and M. A. González-Gutiérrez, Eds., pp. 262-265, Mexico, 2012.

[30] M. González-Elizondo, I. L. López-Enríquez, M. S. GonzálezElizondo, and J. A. Tena-Flores, Plantas Medicinales del Estado de Durango y Zonas Aledañas, Centro Interdisciplinario de Investigación para el Desarrollo Integral Regional Unidad Durango, Instituto Politecnico Nacional, México, 2004.

[31] G. Mendoza-Castelán, Manual de usos terapéuticos y dosificación de flores medicinales de México, Universidad Autónoma Chapingo, Guerrero, México, 2002.

[32] E. Linares, R. A. Bye, and B. Flores, Plantas Medicinales de México. Usos y remedios tradicionales, Instituto de Biología. Universidad Nacional Autónoma de México. México city, Plantas Medicinales de Usos y remedios tradicionales, México, 1999.

[33] M. Á. Bello-González, S. Hernández-Muñoz, M. B. LaraChávez, and R. Salgado-Garciglia, "Plantas útiles de la comunidad indígena Nuevo San Juan Parangaricutiro, Michoacán, México," Polibotánica, vol. 0, no. 39, 2015.

[34] E. Nuñez-Melendez, "Plantas venenosas de Puerto Rico y las que producen dermatitis," in Editorial de la Universidad de Puerto Rico, p. 321, Río Piedras, Puerto Rico, 1996. 
[35] R. Sosa-Gómez, El poder medicinal de las plantas, Ediciones GEMA, Asociación Publicadora Interamericana, Miami, Fl, USA, 2012.

[36] B. Macías-Peacok, M. F. Sußrez-Crespo, A. Berenguer-Rivas et al., "Intoxicaciones por plantas tóxicas atendidas desde un servicio de información toxicológica," Revista Cubana de Plantas Medicinales, vol. 14, no. 2, p. 1, 2009.

[37] G. Mendoza-Castelán, Manual de usos terapéuticos y dosificación de maderas medicinales de México, Universidad Autonoma Chapingo, Guerrero, México, 2003.

[38] V. A. Argueta, A. L. M. Cano, and M. E. Rodarte, Flora Medicinal Indígena de México, Instituto Nacional Indigenista, México city, México, 1994.

[39] B. Valdivia-Correa, C. Gómez-Gutiérrez, M. Uribe, and N. Méndez-Sánchez, "Herbal medicine in Mexico: a cause of hepatotoxicity. A critical review," International Journal of Molecular Sciences, vol. 17, no. 2, article 235, 2016.

[40] S. Nogué-Xarau, P. Sanz-Gallén, and C. Blanché-Vergés, "Intoxicaciones por plantas (I)," Medicina Integral, vol. 36, no. 10, pp. 371-379, 2000.

[41] K. Mejía and F. Rengifo, "Plantas medicinales de uso popular en la Amazonia Peruana," in Agencia Española de cooperación internacional (AECI) \& Instituto de investigaciones de la amazonía peruana (IIAP), p. 286, Lima, Perú, 2000.

[42] D. Godínez-Carballo and G. Volpato, "Plantas medicinales que se venden en el mercado El Río, Camagüey, Cuba," Revista Mexicana de Biodiversidad, vol. 79, no. 1, pp. 243-259, 2008.

[43] Y. Levin, Y. Sherer, H. Bibi, M. Schlesinger, and E. Hay, "Rare Jatropha multifida intoxication in two children," The Journal of Emergency Medicine, vol. 19, no. 2, pp. 173-175, 2000.

[44] C. N. Arroyo, "Plantas tóxicas del estado de Aguascalientes, Taller de Investigación," in Aguascalientes: Universidad Autónoma de Aguascalientes, Mexico, 2007.

[45] A. Herrera, Farmacopea Latinoamericana, México city, Mexico, 1921.

[46] P. J. Cambar, "'Algunos estudios farmacológicos de las plantas medicinales de Honduras," Revista Medica Hondureña, vol. 53, pp. 190-196, 1985.

[47] A. Fierro-Alvarez, A. Pérez-Cardona, C. Guerrero-Borda et al., "Plantas silvestres que se comen en Ixhuatlán del Café, Veracruz," in Editoriales Instituto Nacional de Antropología e Historia, Consejo Nacional de Ciencia y Tecnología, p. 47, Mexico city, Mexico, 2000.

[48] A. Casas, "Silvicultura y domesticación de plantas en Mesoamérica," in Plantas, Cultura y Sociedad: Estudio sobre la Relación entre Seres Humanos y Plantas en los Albores del Siglo XX, B. Rendon-Aguilar, S. Rebollar-Domínguez, J. Caballero-Nieto, and M. A. Martínez-Alfaro, Eds., pp. 123-159, Universidad Autonoma Metropolitana unidad Iztapalapa, Mexico city, Mexico, 2001.

[49] P. Avalos-Peralta, B. García-Bravo, and F. M. Camacho, "Sensitivity to Myroxylon pereirae resin (balsam of Peru). A study of 50 cases," Contact Dermatitis, vol. 52, no. 6, pp. 304-306, 2005.

[50] F. García-Fajardo, L. González-Chévez, P. Hersch-Martínez, and A. Pérez-Cardona, "Plantas medicinales de Ixhuatlán del Café, Veracruz," in Editorial Instituto Nacional de Antropología e Historia (INAH) y Consejo Nacional de Ciencia y Tecnología (CONACyT), vol. 43, Mexico city, Mexico, 2000.

[51] J. D. Guin, R. H. Schosser, and E. W. Rosenberg, "Magnolia grandiflora dermatitis," Dermatologic Clinics, vol. 8, no. 1, pp. 81-84, 1990.
[52] V. León-Jiménez, Elaboración de una base de datos de plantas utilizadas en la medicina tradicional de México [Bachelor thesis], Universidad Autónoma del Estado de Hidalgo, Pachuca, Hidalgo, Mexico, 2005.

[53] M. V. Bermúdez-de Rocha, F. E. Lozano-Meléndez, V. A. Tamez-Rodríguez, G. Díaz-Cuello, and A. Piñedo-López, "Frecuencia de intoxicación con Karwinskia humboldtiana en México," Salud Publica de México, vol. 37, no. 1, pp. 57-62, 1995.

[54] M. E. Arreola-Nava, J. L. Vázquez-Castellanos, and M. E. González-Castañeda, "Geographical factors in the epidemiology of intoxication by Karwinskia (tullidora)," Cadernos Saúde Pública, vol. 16, no. 1, pp. 255-260, 2000.

[55] J. Waizel-Bucay and I. Martinez-Rico, "Algunas plantas usadas en México en padecimiento periodontales," Revista de la Asociación Dental Mexicana, vol. 68, no. 2, pp. 73-88, 2011.

[56] L. Rodriguez-Fragoso, J. Reyes-Esparza, S. W. Burchiel, D. Herrera-Ruiz, and E. Torres, "Risks and benefits of commonly used herbal medicines in Mexico," Toxicology and Applied Pharmacology, vol. 227, no. 1, pp. 125-135, 2008.

[57] M. L. Kulkarni, H. Sreekar, K. S. Keshavamurthy, and N. Shenoy, "Jatropha curcas - Poisoning," The Indian Journal of Pediatrics, vol. 72, no. 1, pp. 75-76, 2005.

[58] B. S. Frank, W. B. Michelson, K. E. Panter, and D. R. Gardner, "Ingestion of poison hemlock (Conium maculatum)," Western Journal of Medicine, vol. 163, no. 6, pp. 573-574, 1995.

[59] E. Biberci, Y. Altuntas, A. Çobanoglu, and A. Alpinar, "Acute respiratory arrest following hemlock (Conium maculatum) intoxication [1]," Journal of Toxicology - Clinical Toxicology, vol. 40, no. 4, pp. 517-518, 2002.

[60] S. K. Verma, G. Dev, A. K. Tyagi, S. Goomber, and G. V. Jain, "Argemone mexicana poisoning: autopsy findings of two cases," Forensic Science International, vol. 115, no. 1-2, pp. 135-141, 2001.

[61] M. A. Montoya-Cabrera, P. Escalante-Galindo, M. MeckesFischer, G. Sanchez-Vaca, E. Flores-Alvarez, and M. ReynosoGarcia, "Envenenamiento mortal causado por el aceite de epazote, Chenopodium graveolens," Gaceta Medica de México, vol. 132, pp. 433-437, 1996.

[62] A. Ingraffea, K. Donohue, C. Wilkel, and V. Falanga, "Cutaneous vasculitis in two patients taking an herbal supplement containing black cohosh," Journal of the American Academy of Dermatology, vol. 56, no. 5, pp. S124-S126, 2007.

[63] S. M. Cohen, A. M. O’Connor, J. Hart, N. H. Merel, and H. S. Te, "Autoimmune hepatitis associated with the use of black cohosh: A case study," Menopause, vol. 11, no. 5, pp. 575-577, 2004.

[64] G. E. Slater, B. H. Rumack, and R. G. Peterson, "Podophyllin poisoning: Systemic toxicity following cutaneous application," Obstetrics \& Gynecology, vol. 52, no. 1, pp. 94-96, 1978.

[65] M. J. Chamberlain, A. L. Reynolds, and W. B. Yeoman, "Medical Memoranda. Toxic Effect of Podophyllum Application in Pregnancy," British Medical Journal, vol. 3, no. 5823, pp. 391-392, 1972.

[66] R. B. Rao and R. S. Hoffman, "Nicotinic toxicity from tincture of blue cohosh (Caulophyllum thalictroides) used as an abortifacient," Veterinary and Human Toxicology, vol. 44, no. 4, pp. 221-222, 2002.

[67] P. Durasnel, L. Vanhuffel, R. Blondé et al., "Severe poisoning by plants used for traditional medicine in Mayotte," Bulletin de la Société de Pathologie Exotique, vol. 107, no. 5, pp. 306-311, 2014.

[68] M. R. Quintanilla and R. Arenas, "Dermatitis por contacto a Metopium brownei (Chechem). Observaciones cl $\varphi$ nicas de 20 casos en Quintana Roo," Dermatología Cosmética, Medica y Quirúrgica, vol. 7, no. 4, pp. 226-233, 2009. 
[69] K. L. Grant, L. V. Boyer, and B. E. Erdman, "Chaparral-induced hepatotoxicity," Integrative Medicine A Clinicican's Journal, vol. 1, no. 2, pp. 83-87, 1998.

[70] C. Fernando, "Poisoning due to Abrus precatorius (jequirity bean)," Anaesthesia, vol. 56, no. 12, pp. 1178-1180, 2001.

[71] D. Subrahmanyan, J. Mathew, and M. Raj, "An unusual manifestation of Abrus precatorius poisoning: A report of two cases," Clinical Toxicology, vol. 46, no. 2, pp. 173-175, 2008.

[72] L. J. DeFrates, J. D. Hoehns, E. L. Sakornbut, D. G. Glascock, and A. R. Tew, "Antimuscarinic intoxication resulting from the ingestion of moonflower seeds," Annals of Pharmacotherapy, vol. 39, no. 1, pp. 173-176, 2005.

[73] Missouri Botanical Garden, “Tropicos," 2017, http://www .tropicos.org.

[74] A. D. Ologhobo, B. L. Fetuga, and O. O. Tewe, "The cyanogenic glycoside contents of raw and processed limabean varieties," Food Chemistry, vol. 13, no. 2, pp. 117-128, 1984.

[75] P. Cressey, D. Saunders, and J. Goodman, "Cyanogenic glycosides in plant-based foods available in New Zealand," Food Additives and Contaminants - Part A Chemistry, Analysis, Control, Exposure and Risk Assessment, vol. 30, no. 11, pp. 1946-1953, 2013.

[76] A. H. Md. Zulfiker, M. Siddiqua, L. Nahar et al., "In vitro antibacterial, antifungal and cytotoxic activity of Scoparia dulcis L," International Journal of Pharmacy and Pharmaceutical Sciences, vol. 3, no. 2, pp. 198-203, 2011.

[77] P. G. Susana, R. C. Aarland, M. G. C. Lara, M. E. Jiménez Lara, and M. E. José Alberto, "Toxicity analysis, phytochemical and pharmacological study of the plant known as Mora herb, collected at the environmental education center of yautlica (CEA-Yautlica)," Asian Journal of Plant Sciences, vol. 12, no. 4, pp. 159-164, 2013.

[78] R. W. Bussmann, G. Malca, A. Glenn et al., "Toxicity of medicinal plants used in traditional medicine in Northern Peru," Journal of Ethnopharmacology, vol. 137, no. 1, pp. 121-140, 2011.

[79] F. G. Coe, D. M. Parikh, and C. A. Johnson, "Alkaloid presence and brine shrimp (Artemia salina) bioassay of medicinal species of eastern Nicaragua," Pharmaceutical Biology, vol. 48, no. 4, pp. 439-445, 2010.

[80] S.-G. Luis-Benjamín, C.-M. Irais, B.-R. Claudia-Guadalupe et al., "Antimicrobial activity and toxicity of plants from northern Mexico," Indian Journal of Traditional Knowledge, vol. 16, no. 2, pp. 203-207, 2017.

[81] J. E. Espitia-Baena, H. D. R. Duran-Sandoval, J. FandiñoFranky, F. Díaz-Castillo, and H. A. Gómez-Estrada, "Chemistry and biology of ethanol extract from the epicarp of Crescentia cujete L. (totumo)," Revista Cubana de Plantas Medicinales, vol. 16, no. 4, pp. 337-346, 2011.

[82] D. Raya-González, J. Chávez Duran, S. E. Urrutia Hernández et al., "Toxicological study of an aqueous extract from Enterolobium cyclocarpum (Jacq.) Griseb. duramen," Revista Cubana de Plantas Medicinales, vol. 13, no. 3, pp. 1-8, 2008.

[83] J. E. Espitia-Baena, S. M. Robledo-Restrepo, B. S. CuadradoCano, H. R. Duran-Sandoval, and H. A. Gómez-Estrada, "Perfil fitoquímico, actividad anti-Leishmania, hemolítica y toxicológica de Cordia dentata Poir. y Heliotropium indicum L," Revista Cubana de Plantas Medicinales, vol. 19, no. 3, pp. 208224, 2014.

[84] M. Canales, T. Hernández, R. Serrano et al., "Antimicrobial and general toxicity activities of Gymnosperma glutinosum: A comparative study," Journal of Ethnopharmacology, vol. 110, no. 2, pp. 343-347, 2007.
[85] C. H. Tokarnia, A. G. Armién, P. V. Peixoto, J. D. Barbosa, M. De Farias Brito, and J. Döbereiner, "Experiments on the toxicity of some ornamental plants in cattle," Pesquisa Veterinária Brasileira, vol. 16, no. 1, pp. 5-20, 1996.

[86] E. Galarraga Montes and J. M. Amaro-Luis, "Icosandrin, a novel peltogynoid from the fruits of Phytolacca icosandra (Phytolaccaceae)," Natural Product Research (Formerly Natural Product Letters), vol. 30, no. 1, pp. 89-94, 2016.

[87] G. Lopes, T. M. S. Da Silva, and A. Echevarria, “Toxicity from crude extracts and glycoalkaloid fractions of Solanum spp. Against Artemia salina and Biomphalaria glabrata," Revista Virtual de Química, vol. 8, no. 1, pp. 141-156, 2016.

[88] A. Sowemimo, L. Venables, M. Odedeji, T. Koekemoer, M. Van De Venter, and L. Hongbing, "Antiproliferative mechanism of the methanolic extract of Enterolobium cyclocarpum (Jacq.) Griseb. (Fabaceae)," Journal of Ethnopharmacology, vol. 159, pp. 257-261, 2015.

[89] A. Lagarto Parra, R. Silva Yhebra, I. Guerra Sardiñas, and L. Iglesias Buela, "Comparative study of the assay of Artemia salina L. and the estimate of the medium lethal dose (LD50 value) in mice, to determine oral acute toxicity of plant extracts," Phytomedicine, vol. 8, no. 5, pp. 395-400, 2001.

[90] M. A. Karim, A. A. Sidddiqui, G. H. Rizwani, M. F. Khan, and M. Ahmed, "Toxicity of Sanguinaria canadensis as compared to Aloe vera against brine shrimp (Artemia salina) using the probit methodology," Journal of Pharmacy and Nutrition Sciences, vol. 5, no. 1, pp. 1-4, 2015.

[91] M. C. Jacobo-Salcedo, A. J. Alonso-Castro, L. A. Salazar-Olivo et al., "Antimicrobial and cytotoxic effects of Mexican medicinal plants," Natural Product Communications, vol. 6, no. 12, pp. 1925-1928, 2011.

[92] F. M. Torrico, J. Gambay, A. I. Suárez, R. S. Compagnone, and A. I. Suárez, "Estudio toxicológico de Cnidoscolus chayamansa Mc Vaugh," Revista de la Facultad de Farmacia, vol. 66, no. 2, pp. 58-66, 2003.

[93] G. M. de Queiroz, T. M. de Souza-Moreira, H. R. N. Salgado et al., "Antimicrobial activity and toxicity in vitro and in vivo of Equisetum hyemale extracts," Revista de Ciências Farmacêuticas Básica e Aplicada, vol. 35, no. 4, pp. 559-563, 2014.

[94] R. Guillopé, M. Escobar-Khondiker, V. Guérineau, O. Laprévote, G. U. Höglinger, and P. Champy, "Kaurenoic acid from pulp of Annona cherimolia in regard to annonaceae-induced parkinsonism," Phytotherapy Research, vol. 25, no. 12, pp. 18611864, 2011.

[95] A. F. Valdés, J. Mendiola, D. Acuña, Y. caballero, R. Scull, and Y. Gutiérrez, "Antimalarial activity and cytotoxicity of hydroalcoholic extracts from six plant species used in Cuban traditional medicine," Revista Cubana de Medicina Tropical, vol. 63, no. 1, pp. 52-57, 2011.

[96] A. Ramos, R. Rivero, A. Visozo, J. Piloto, and A. García, "Parthenin, a sesquiterpene lactone of Parthenium hysterophorus L. is a high toxicity clastogen," Mutation Research, vol. 514, no. 1-2, pp. 19-27, 2002.

[97] E. A. Varanda, T. R. Calvo, C. R. P. Cardoso et al., "Mutagenic activity of Indigofera truxillensis and I. suffruticosa aerial parts," Evidence-Based Complementary and Alternative Medicine, vol. 2011, Article ID 323276, 2011.

[98] M. Déciga-Campos, M. Arriaga-Alba, R. Ventura-Martínez, B. Aguilar-Guadarrama, and M. Y. Rios, "Pharmacological and toxicological profile of extract from Heliopsis longipes and affinin," Drug Development Research, vol. 73, no. 3, pp. 130-137, 2012. 
[99] L. D. Da Costa E Silva, L. C. L. V. Rodrigues, V. R. Dos Santos et al., "Evaluation of mutagenic and genotoxic activities of lobeline and its modulation on genomic instability induced by ethanol," Life Sciences, vol. 103, no. 2, pp. 73-78, 2014.

[100] C. M. Mattana, M. A. Cangiano, S. E. Satorres, L. E. Alcaráz, and A. L. Laciar, "Potential genotoxicity of zinnia peruviana extract," Pharmacologyonline, vol. 2016, no. 2, pp. 72-80, 2016.

[101] A. L. Gindri, L. B. De Souza, R. C. Cruz, A. A. Boligon, M. M. Machado, and M. L. Athayde, "Genotoxic evaluation, secondary metabolites and antioxidant capacity of leaves and roots of Urera baccifera Gaudich (Urticaceae)," Natural Product Research (Formerly Natural Product Letters), vol. 28, no. 23, pp. 2214-2216, 2014.

[102] J. G. Avila-Acevedo, A. M. García-Bores, F. Martínez-Ramírez et al., "Antihyperglycemic effect and genotoxicity of Psittacanthus calyculatus extract in streptozotocin-induced diabetic rats," Boletin Latinoamericano y del Caribe de Plantas Medicinales y Aromaticas, vol. 11, no. 4, pp. 345-353, 2012.

[103] R. Cariño-Cortés, J. A. Gayosso-De-Lucio, M. I. Ortiz et al., "Antinociceptive, genotoxic and histopathological study of Heliopsis longipes S.F. Blake in mice," Journal of Ethnopharmacology, vol. 130, no. 2, pp. 216-221, 2010.

[104] Organization for Economic Cooperation and Development, Guideline for Testing of Chemicals, Test guideline 423: acute oral toxicity, acute toxic class methods, 2012.

[105] A. S. Awaad, N. A. Al-Jaber, G. A. Soliman et al., "New biological activities of Casimiroa edulis leaf extract and isolated compounds," Phytotherapy Research, vol. 26, no. 3, pp. 452-457, 2012.

[106] R. V. García-Rodríguez, G. A. Gutiérrez-Rebolledo, E. MéndezBolaina et al., "Cnidoscolus chayamansa Mc Vaugh, an important antioxidant, anti-inflammatory and cardioprotective plant used in Mexico," Journal of Ethnopharmacology, vol. 151, no. 2, pp. 937-943, 2014.

[107] G. A. Gutiérrez-Rebolledo, L. Garduño-Siciliano, R. V. GarcíaRodríguez et al., "Anti-inflammatory and toxicological evaluation of Moussonia deppeana (Schldl. \& Cham) Hanst and Verbascoside as a main active metabolite," Journal of Ethnopharmacology, vol. 187, pp. 269-280, 2016.

[108] A. H. Shah, S. Qureshi, and A. M. Ageel, "Toxicity studies in mice of ethanol extracts of Foeniculum vulgare fruit and Ruta chalepensis aerial parts," Journal of Ethnopharmacology, vol. 34, no. 2-3, pp. 167-172, 1991.

[109] O. A. Olajide, S. O. Awe, and J. M. Makinde, "Pharmacological screening of the methanolic extract of Chenopodium ambrosioides," Fitoterapia, vol. 68, no. 6, pp. 529-532, 1997.

[110] S. R. Tamboli and R. S. Pandit, "Acute toxicity evaluation of Rauvolfia tetraphylla leaf extract in rat by up and down method," International Journal of Pharmaceutical and Clinical Research, vol. 6, no. 4, pp. 316-319, 2014.

[111] J. F. Palacios-Espinosa, O. Arroyo-García, G. García-Valencia, E. Linares, R. Bye, and I. Romero, "Evidence of the antiHelicobacter pylori, gastroprotective and anti-inflammatory activities of Cuphea aequipetala infusion," Journal of Ethnopharmacology, vol. 151, no. 2, pp. 990-998, 2014.

[112] K. Sirisha, Y. Rajendra, P. Gomathi, K. Soujanya, and N. Yasmeen, "Antioxidant and anti-inflammatory activities of flowers of plumeria rubra l. f. rubra and plumeria rubra f. lutea: A comparative study," Research Journal of Pharmaceutical, Biological and Chemical Sciences, vol. 4, no. 4, pp. 743-756, 2013.
[113] C. Anesini, J. Boccio, G. Cremaschi et al., "In vivo antitumoural activity and acute toxicity study of Larrea divaricata Cav. extract," Phytotherapy Research, vol. 11, no. 7, pp. 521-523, 1997.

[114] D. Kumar, J. Singh, A. Baghotia, and S. Kumar, "Anticonvulsant effect of the ethanol extract of Caesalpinia pulcherrima (L.) Sw., Fabaceae, leaves," Revista Brasileira de Farmacognosia, vol. 20, no. 5, pp. 751-755, 2010.

[115] S. Kumar, J. Singh, A. Baghotia et al., "Antifertility potential of the ethanolic extract of Caesalpinia pulcherrima Linn. leaves," Asian Pacific Journal of Reproduction, vol. 2, no. 2, pp. 90-92, 2013.

[116] F. Kengni, D. Tala, M. Djimeli et al., "In vitro antimicrobial activity of Harungana madagascriensis and Euphorbia prostrata extracts against some pathogenic Salmonella sp," International Journal of Biological and Chemical Sciences, vol. 7, no. 3, p. 1106, 2013.

[117] S. Sarkiyayi, S. Ibrahim, and M. S. Abubakar, "Toxicological studies of Ceiba pentandra Linn," African Journal of Biochemistry Research, vol. 3, no. 7, pp. 279-281, 2009.

[118] V. Dutt, V. J. Dhar, and A. Sharma, "Antianxiety activity of Gelsemium sempervirens," Pharmaceutical Biology, vol. 48, no. 10, pp. 1091-1096, 2010.

[119] M. Hernández-Ortega, A. Ortiz-Moreno, M. D. HernándezNavarro, G. Chamorro-Cevallos, L. Dorantes-Alvarez, and H. Necoechea-Mondragón, "Antioxidant, antinociceptive, and anti-inflammatory effects of carotenoids extracted from dried pepper (Capsicum annuum L.)," Journal of Biomedicine and Biotechnology, vol. 2012, Article ID 524019, 2012.

[120] T. A. Abere, C. J. Okoye, F. O. Agoreyo et al., "Antisickling and toxicological evaluation of the leaves of Scoparia dulcis Linn (Scrophulariaceae)," BMC Complementary and Alternative Medicine, vol. 15, article 414, 2015.

[121] M. Moniruzzaman, M. Atikur Rahman, and A. Ferdous, "Evaluation of sedative and hypnotic activity of ethanolic extract of Scoparia dulcis Linn.," Evidence-Based Complementary and Alternative Medicine, vol. 2015, Article ID 873954, 6 pages, 2015.

[122] C. M. S. Dutok, C. A. Berenguer-Rivas, E. Rodríguez-Leblanch et al., "Acute toxicity and dermal and eye irritation of the aqueous and hydroalcoholic extracts of the seeds of "zapote" pouteria mammosa (L.) cronquist," The Scientific World Journal, vol. 2015, Article ID 642906, 2015.

[123] B. Harish-Babu, S. Mohana-Lakshmi, and A. Saravana-Kumar, "Studies on phytochemical and anticonvulsant property of Martyniya annua Linn,” vol. 1, pp. 82-86, 2010.

[124] C. D. Zavala, M. L. Carrillo I, B. Alvarado S, and A. O. Sánchez $\mathrm{Ch}$, "Evaluation of the acute toxicity of an alcoholic extract from tarbush leaves (Flourensia cernua)," Revista Mexicana de Ciencias Farmaceuticas, vol. 41, no. 3, pp. 50-54, 2010.

[125] V. Sharma and G. Rajani, "Evaluation of Caesalpinia pulcherrima Linn. for anti-inflammatory and antiulcer activities," Indian Journal of Pharmacology, vol. 43, no. 2, pp. 168-171, 2011.

[126] K. Devaki, U. Beulah, G. Akila, and V. K. Gopalakrishnan, "Effect of aqueous extract of Passiflora edulis on biochemical and hematological parameters of Wistar Albino rats," Toxicology International, vol. 19, no. 1, pp. 63-67, 2012.

[127] B. E. Bastidas-Ramírez, N. Navarro-Ruíz, J. D. QuezadaArellano, B. Ruíz-Madrigal, M. T. Villanueeva-Michel, and P. Garzón, "Anticonvulsant effects of Magnolia grandiflora L. in the rat," Journal of Ethnopharmacology, vol. 61, no. 2, pp. 143152, 1998.

[128] C. S. Shastry, M. Bhalodia Maulik, and B. J. Aswathanarayana, "Antivenom activity of ethanolic extract of Crescentia cujete 
fruit," International Journal of Phytomedicine, vol. 4, no. 1, pp. 108-114, 2012.

[129] B. S. Kumar, K. Lakshman, R. Nandeesh et al., "In vitro alpha-amylase inhibition and in vivo antioxidant potential of Amaranthus spinosus in alloxan-induced oxidative stress in diabetic rats," Saudi Journal of Biological Sciences, vol. 18, no. 1, pp. 1-5, 2011.

[130] S. Gupta, V. K. Khanna, A. Maurya et al., "Bioactivity guided isolation of antipsychotic constituents from the leaves of Rauwolfia tetraphylla L.," Fitoterapia, vol. 83, no. 6, pp. 1092-1099, 2012.

[131] M. Z. Pérez-González, G. A. Gutiérrez-Rebolledo, L. YépezMulia, I. S. Rojas-Tomé, J. Luna-Herrera, and M. A. JiménezArellanes, "Antiprotozoal, antimycobacterial, and anti-inflammatory evaluation of Cnidoscolus chayamansa (Mc Vaugh) extract and the isolated compounds," Biomedicine \& Pharmacotherapy, vol. 89, pp. 89-97, 2017.

[132] M. I. Khan, K. M. Denny Joseph, Muralidhara, H. P. Ramesh, P. Giridhar, and G. A. Ravishankar, "Acute, subacute and subchronic safety assessment of betalains rich Rivina humilis L. berry juice in rats," Food and Chemical Toxicology, vol. 49, no. 12, pp. 3154-3157, 2011.

[133] F. Nikkon, M. R. Habib, Z. A. Saud, and M. R. Karim, “Tagetes erecta Linn. and its mosquitocidal potency against Culex quinquefasciatus," Asian Pacific Journal of Tropical Biomedicine, vol. 1, no. 3, pp. 186-188, 2011.

[134] F. Jaramillo-Juárez, M. L. Rodríguez-Vázquez, J. MuñozMartínez et al., "The ATP levels in kidneys and blood are mainly decreased by acute ingestion of tullidora (Karwinskia humboldtiana)," Toxicon, vol. 46, no. 1, pp. 99-103, 2005.

[135] M. G. B. Silva, T. P. Aragão, C. F. B. Vasconcelos et al., "Acute and subacute toxicity of Cassia occidentalis L. stem and leaf in Wistar rats," Journal of Ethnopharmacology, vol. 136, no. 2, pp. 341-346, 2011.

[136] K. B. Harikumar, C. V. Nimita, K. C. Preethi, R. Kuttan, M. L. Shankaranarayana, and J. Deshpande, "Toxicity profile of lutein and lutein ester isolated from marigold flowers (Tagetes erecta)," International Journal of Toxicology, vol. 27, no. 1, pp. 1-9, 2008.

[137] S. R. Mariz, M. S. T. Araújo, G. S. Cerqueira et al., "Histopathological evaluation in rats after acute treatment with the ethanol extract from aerial parts of Jatropha gossypiifolia L.," Revista Brasileira de Farmacognosia, vol. 18, no. 2, pp. 213-216, 2008.

[138] O. A. Salako, A. J. Akindele, O. M. Shitta, O. O. Elegunde, and O. O. Adeyemi, "Antidiarrhoeal activity of aqueous leaf extract of Caladium bicolor (Araceae) and its possible mechanisms of action," Journal of Ethnopharmacology, vol. 176, pp. 225-231, 2015.

[139] E. Aguirre-Hernández, A. L. Martínez, M. E. González-Trujano, J. Moreno, H. Vibrans, and M. Soto-Hernández, "Pharmacological evaluation of the anxiolytic and sedative effects of Tilia americana L. var. mexicana in mice," Journal of Ethnopharmacology, vol. 109, no. 1, pp. 140-145, 2007.

[140] G. Pérez-Ortega, M. E. González-Trujano, G. E. Ángeles-López, F. Brindis, H. Vibrans, and R. Reyes-Chilpa, "Tagetes lucida Cav.: Ethnobotany, phytochemistry and pharmacology of its tranquilizing properties," Journal of Ethnopharmacology, vol. 181, pp. 221-228, 2016.

[141] M. Singh, V. Kumar, I. Singh, V. Gauttam, and A. Kalia, "Antiinflammatory activity of aqueous extract of Mirabilis jalapa Linn. leaves," Pharmacognosy Research, vol. 2, no. 6, p. 364, 2010.

[142] B. Badilla, G. Mora, and L. J. Poveda, "Anti-inflammatory activity of aqueous extracts of five Costa Rican medicinal plants in Sprague-Dawley rats," Revista de Biología Tropical, vol. 47, no. 4, pp. 723-727, 1999.

[143] A. J. Alonso-Castro, M. D. C. Juárez-Vázquez, F. Domínguez et al., "The antitumoral effect of the American mistletoe Phoradendron serotinum (Raf.) M.C. Johnst. (Viscaceae) is associated with the release of immunity-related cytokines," Journal of Ethnopharmacology, vol. 142, no. 3, pp. 857-864, 2012.

[144] P. J. Becci, H. Schwartz, H. H. Barnes, and G. L. Southard, "Short-term toxicity studies of sangulnarlne and of two alkaloid extracts of Sanguinaria Canadensis L," Journal of Toxicology and Environmental Health, vol. 20, no. 1-2, pp. 199-208, 1987.

[145] Muralidhara and K. Narasimhamurthy, "Non-mutagenicity of capsaicin in Albino mice," Food and Chemical Toxicology, vol. 26, no. 11-12, pp. 955-958, 1988.

[146] M. E. Garín-Aguilar, J. E. Ramírez Luna, M. Soto-Hernández, G. Valencia del Toro, and M. Martínez Vázquez, "Effect of crude extracts of Erythrina americana Mill. on aggressive behavior in rats," Journal of Ethnopharmacology, vol. 69, no. 2, pp. 189-196, 2000.

[147] C.-Y. Li, R. K. Devappa, J.-X. Liu, J.-M. Lv, H. P. S. Makkar, and K. Becker, "Toxicity of Jatropha curcas phorbol esters in mice," Food and Chemical Toxicology, vol. 48, no. 2, pp. 620-625, 2010.

[148] L. A. Chami, R. Méndez, B. Chataing, J. O’Callaghan, A. Usubillaga, and L. LaCruz, "Toxicological effects of $\alpha$-solamargine in experimental animals," Phytotherapy Research, vol. 17, no. 3, pp. 254-258, 2003.

[149] K. V. Rao and T. L. Davis, "Constituents of Magnolia grandiflora. III. Toxic principle of the wood," Journal of Natural Products, vol. 45, no. 3, pp. 283-287, 1982.

[150] W. C. Bowman and I. S. Sanghvi, "Pharmacological actions of hemlock (Conium maculatum) alkaloids," Journal of Pharmacy and Pharmacology, vol. 15, no. 1, pp. 1-25, 1963.

[151] T. R. Narasimhan, B. S. K. Murthy, N. Harindranath, and P. V. S. Rao, "Characterization of a toxin from Parthenium hysterophorus and its mode of excretion in animals," Journal of Biosciences, vol. 6, no. 5, pp. 729-738, 1984.

[152] T. Glinsukon, V. Stitmunnaithum, C. Toskulkao, T. Buranawuti, and V. Tangkrisanavinont, "Acute toxicity of capsaicin in several animal species," Toxicon, vol. 18, no. 2, pp. 215-220, 1980.

[153] R. Davicino, A. Mattar, Y. Casali, C. Porporatto, S. G. Correa, and B. Micalizzi, "In vivo immunomodulatory effects of aqueous extracts of Larrea divaricata Cav.," Immunopharmacology and Immunotoxicology, vol. 29, no. 3-4, pp. 351-366, 2007.

[154] F. Jaramillo, V. M. L. Rodríguez, C. M. G. Castillo et al., "Hepatic and blood coagulation damage produced by administration of ripe fruit from the tullidora plant (Karwinskia humboldtiana) in the rat," Revista Mexicana de Ciencias Farmaceuticas, vol. 40, no. 1, pp. 28-34, 2009.

[155] E. Maluf, H. M. T. Barros, M. L. Frochtengarten, R. Benti, and J. R. Leite, "Assessment of the hypnotic/sedative effects and toxicity of Passiflora edulis aqueous extract in rodents and humans," Phytotherapy Research, vol. 5, no. 6, pp. 262-266, 1991.

[156] K. Carcano-Diaz, A. Garcia-Garcia, J. C. Segoviano-Ramirez, H. Rodriguez-Rocha, M. D. J. Loera-Arias, and J. Garcia-Juarez, "Damage to pancreatic acinar cells and preservation of islets of langerhans in a rat model of acute pancreatitis induced by karwinskia humboldtiana (Buckthorn)," Histology and Histopathology, vol. 31, no. 9, pp. 1001-1010, 2016.

[157] S. R. Tamboli and R. S. Pandit, "Subacute toxicity evaluation of Rauvolfia tetraphylla methanolic leaf extract in Sprague dawley rat," International Journal of Pharmaceutical Sciences Review and Research, vol. 34, no. 1, article no. 24, pp. 152-157, 2015. 
[158] M. Cid-Hernández, A. C. Ramírez-Anguiano, G. G. Ortiz et al., "Mitochondrial atpase activity and membrane fluidity changes in rat liver in response to intoxication with buckthorn (karwinskia humboldtiana)," Biological Research, vol. 48, 2015.

[159] J. N. Ogbulie, C. C. Ogueke, I. C. Okoli, and B. N. Anyanwu, "Antibacterial activities and toxicological potentials of crude ethanolic extracts of Euphorbia hirta," African Journal of Biotechnology, vol. 6, no. 13, pp. 1544-1548, 2007.

[160] S. R. Hashemi, I. Zulkifli, H. Davoodi, Z. Zunita, and M. Ebrahimi, "Growth performance, intestinal microflora, plasma fatty acid profile in broiler chickens fed herbal plant (Euphorbia hirta) and mix of acidifiers," Animal Feed Science and Technology, vol. 178, no. 3-4, pp. 167-174, 2012.

[161] M. L. Omnell, F. R. P. Sim, R. F. Keeler, L. C. Harne, and K. S. Brown, "Expression of Veratrum alkaloid teratogenicity in the mouse," Teratology, vol. 42, no. 2, pp. 105-119, 1990.

[162] J. Gonzales, V. Benavides, R. Rojas, and J. Pino, "Efecto embriotóxico y teratogénico de Ruta chalepensis L. ruda, en ratón (Mus musculus)," Revista Peruana de Biología, vol. 13, no. 3, 2013.

[163] R. Zeichen de Sa, A. Rey, E. Argañaraz, and E. Bindstein, "Perinatal toxicology of Ruta chalepensis (Rutaceae) in mice," Journal of Ethnopharmacology, vol. 69, no. 2, pp. 93-98, 2000.

[164] D. T. Victorien, K. Jean Robert, D. T. Jacques et al., "Hemostatic activity screening and skin toxicity of sap of Jatropha multifida L. (Euphorbiaceae) used in traditional medicine (Benin)," Asian Pacific Journal of Tropical Disease, vol. 2, no. 2, pp. S927-S932, 2012.

[165] W. Adolf, H. J. Opferkuch, and E. Hecker, "Irritant phorbol derivatives from four Jatropha species," Phytochemistry, vol. 23, no. 1, pp. 129-132, 1984.

[166] A. L. Meyer Albiero, J. A. Aboin Sertié, and E. M. Bacchi, "Antiulcer activity of Sapindus saponaria L. in the rat," Journal of Ethnopharmacology, vol. 82, no. 1, pp. 41-44, 2002.

[167] D. Dabhadkar, V. Zade, S. Dawada, M. Dhore, and M. Kodape, "Effect of alcoholic pod extract of Plumeria rubra on biochemical and haematologicalparameters of female albino rats," International Journal of Pharmaceutical Sciences Review and Research, vol. 19, no. 1, pp. 69-74, 2013.

[168] J.-J. Jang, D. E. Devor, D. L. Logsdon, and J. M. Ward, “A 4-week feeding study of ground red chilli (Capsicum annuum) in male B6C3F1 mice," Food and Chemical Toxicology, vol. 30, no. 9, pp. 783-787, 1992.

[169] A. A. Adedapo, O. A. Omoloye, and O. G. Ohore, "Studies on the toxicity of an aqueous extract of the leaves of Abrus precatorius in rats," Onderstepoort Journal of Veterinary Research, vol. 74, no. 1, pp. 31-36, 2007.

[170] S. R. Mariz, G. S. Cerqueira, W. C. Araújo et al., "Chronic toxicologic study of the ethanolic extract of the aerial parts of Jatropha gossypiifolia in rats," Revista Brasileira de Farmacognosia, vol. 22, no. 3, pp. 663-668, 2012.

[171] M. Yao, H. E. Ritchie, and P. D. Brown-Woodman, "A reproductive screening test of goldenseal," Birth Defects Research Part B - Developmental and Reproductive Toxicology, vol. 74, no. 5, pp. 399-404, 2005.

[172] M. A. Medeiros, F. Riet-Correa, F. P. M. Dantas, J. R. S. Santos, and R. M. T. Medeiros, "Efeitos teratogênicos de prosopis juliflora em ratos e análise da toxicidad e das vagens," Pesquisa Veterinaria Brasileira, vol. 34, no. 11, pp. 1089-1093, 2014.

[173] D. Dabhadkar and V. Zade, "Abortifacient activity of Plumeria rubra (Linn) pod extract in female albino rats," Indian Journal of Experimental Biology (IJEB), vol. 50, no. 10, pp. 702-707, 2012.
[174] F. B. Mello, D. Jacobus, K. Carvalho, and J. R. B. Mello, "Effects of Lantana camara (Verbenaceae) on general reproductive performance and teratology in rats," Toxicon, vol. 45, no. 4, pp. 459-466, 2005.

[175] National Toxicology Program, Toxicology and carcinogenesis studies of goldenseal root powder (Hydrastis Canadensis) in F344/N rats and B6C3F1 mice (feed studies), vol. 562, National Toxicology Program Technical Report Series, 2010.

[176] C. A. Naranjo, U. Busto, and E. M. Sellers, "A method for estimating the probability of adverse drug reactions," Clinical Pharmacology \& Therapeutics, vol. 30, no. 2, pp. 239-245, 1981.

[177] Mexican Official Norm NOM-220-SSA1-2016, Pharmacovigilance Installation and Operation, Secretary of Health, Mexico City, Mexico, 2013.

[178] G. Danan and C. Benichou, "Causality assessment of adverse reactions to drugs-I: a novel method based on the conclusions of international consensus meetings: application to druginduced liver injuries," Journal of Clinical Epidemiology, vol. 46, no. 11, pp. 1323-1330, 1993.

[179] E. P. Krenzelok, T. D. Jacobsen, and J. M. Aronis, "Poinsettia exposures have good outcomes-Just as we thought," The American Journal of Emergency Medicine, vol. 14, no. 7, pp. 671$674,1996$.

[180] F. Borrelli and E. Ernst, "Black cohosh (Cimicifuga racemosa): a systematic review of adverse events," American Journal of Obstetrics \& Gynecology, vol. 199, no. 5, pp. 455-466, 2008.

[181] R. Teschke, A. Schwarzenboeck, W. Schmidt-Taenzer, A. Wolff, and K. Hennermann, "Herb induced liver injury presumably caused by black cohosh: a survey of initially purported cases and herbal quality specifications," Annals of Hepatology, vol. 10, no. 3, pp. 249-259, 2011.

[182] A. Schnuch, H. Lessmann, J. Geier, P. J. Frosch, and W. Uter, "Contact allergy to fragrances: Frequencies of sensitization from 1996 to 2002. Results of the IVDK," Contact Dermatitis, vol. 50, no. 2, pp. 65-76, 2004.

[183] J. G. Marks Jr., D. V. Belsito, V. A. DeLeo et al., "North American contact dermatitis group patch-test results, 1996-1998 [8]," JAMA Dermatology, vol. 136, no. 2, pp. 272-273, 2000.

[184] S. Wöhrl, W. Hemmer, M. Focke, M. Götz, and R. Jarisch, “The significance of fragrance mix, balsam of Peru, colophony and propolis as screening tools in the detection of fragrance allergy," British Journal of Dermatology, vol. 145, no. 2, pp. 268-273, 2001.

[185] A. Trattner and M. David, "Patch testing with fine fragrances: Comparison with fragrance mix, balsam of Peru and a fragrance series," Contact Dermatitis, vol. 49, no. 6, pp. 287-289, 2003.

[186] P. Turić, J. Lipozenčić, V. Milavec-Puretić, and S. M. Kulišić, "Contact allergy caused by fragrance mix and Myroxylon pereirae (balsam of Peru) - A retrospective study," Collegium Antropologicum, vol. 35, no. 1, pp. 83-87, 2011.

[187] M. Eddleston, S. Attapattu, S. A. M. Kularatne et al., "Acute yellow oleander (Thevetia peruviana) poisoning: Cardiac arrhythmias, electrolyte disturbances, and serum cardiac glycoside concentrations on presentation to hospital," Heart, vol. 83, no. 3, pp. 301-306, 2000.

[188] J. F. Rivero-Cruz, D. Chavez, B. Hernandez Bautista, A. L. Anaya, and R. Mata, "Separation and characterization of Metopium brownei urushiol components," Phytochemistry, vol. 45, no. 5, pp. 1003-1008, 1997.

[189] M. Eddleston, C. A. Ariaratnam, W. P. Meyer et al., "Epidemic of self-poisoning with seeds of the yellow oleander tree (Thevetia peruviana) in northern Sri Lanka," Tropical Medicine \& International Health, vol. 4, no. 4, pp. 266-273, 1999. 
[190] M. Guerrero, A. Piñeyro, and N. Waksman, "Extraction and quantification of toxins from Karwinskia humboldtiana (Tullidora)," Toxicon, vol. 25, no. 5, pp. 565-568, 1987.

[191] P. A. Lancaster and J. E. Brooks, "Cassava leaves as human food," Economic Botany, vol. 37, no. 3, pp. 331-348, 1983.

[192] J. M. McMahon, W. L. White, and R. T. Sayre, "Cyanogenesis in cassava (Manihot esculenta Crantz)," Journal of Experimental Botany, vol. 46, no. 288, pp. 731-741, 1995.

[193] S. Husain, R. Narsimha, and R. N. Rao, "Separation, identification and determination of sanguinarine in argemone and other adulterated edible oils by reversed-phase high-performance liquid chromatography," Journal of Chromatography A, vol. 863, no. 1, pp. 123-126, 1999.

[194] F. Stickel and D. Shouval, "Hepatotoxicity of herbal and dietary supplements: an update," Archives of Toxicology, vol. 89, no. 6, pp. 851-865, 2015.

[195] S. R. Lin, L. P. Cai, and D. Y. Lin, "Effects of electroacupuncture of "Zusanli" (ST 36) on gastric mucosal blood flow, NO and ET contents in gastric mucosal injury rats," Acupuncture Research, vol. 31, no. 2, pp. 110-112, 2006.

[196] S. P. Myers, "Interactions between complementary medicines and warfarin," Australian Prescriber, vol. 25, no. 3, pp. 54-56, 2002. 


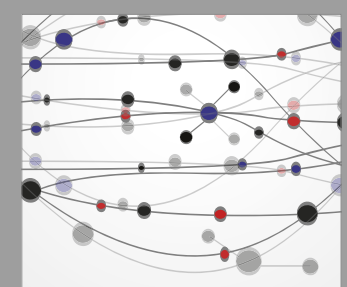

The Scientific World Journal
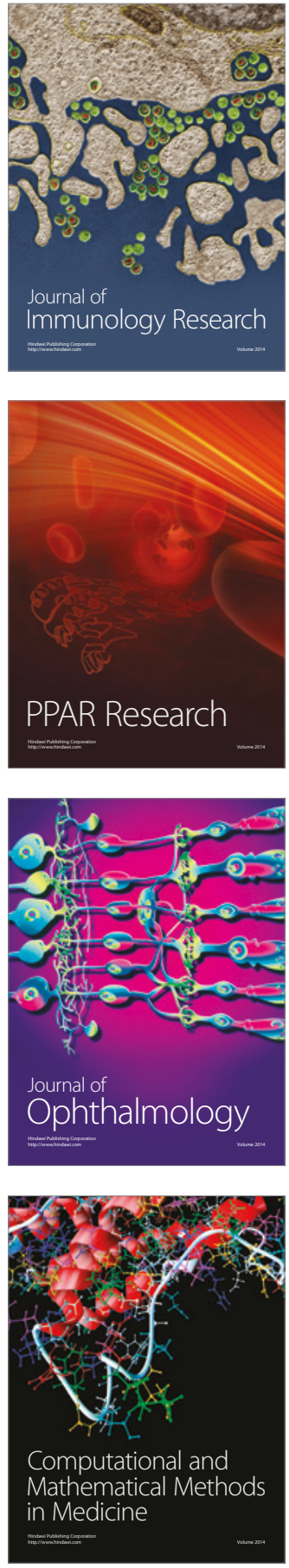

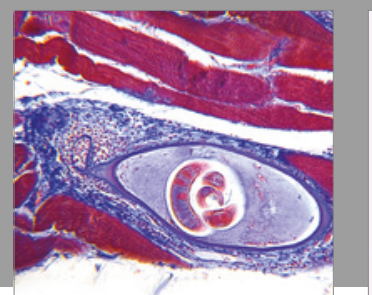

Gastroenterology Research and Practice
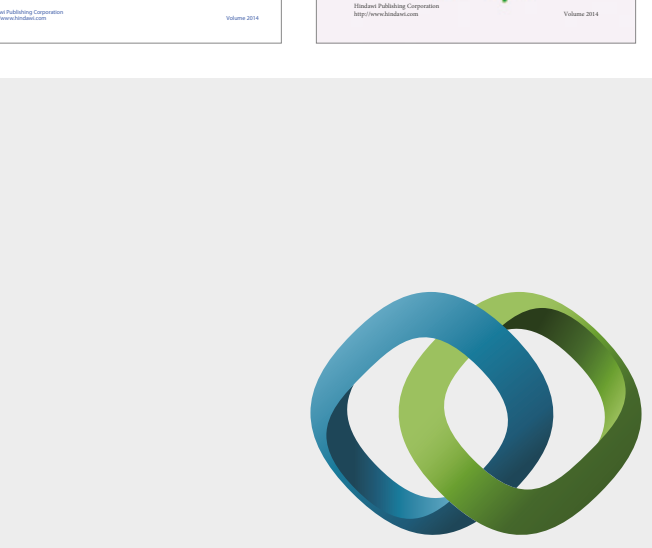

\section{Hindawi}

Submit your manuscripts at

https://www.hindawi.com
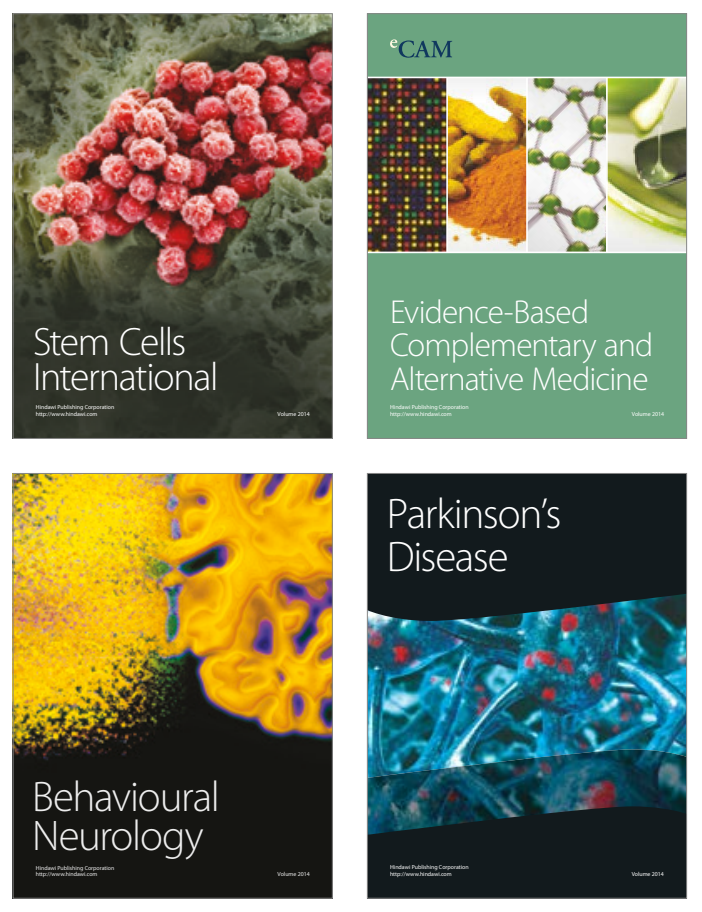
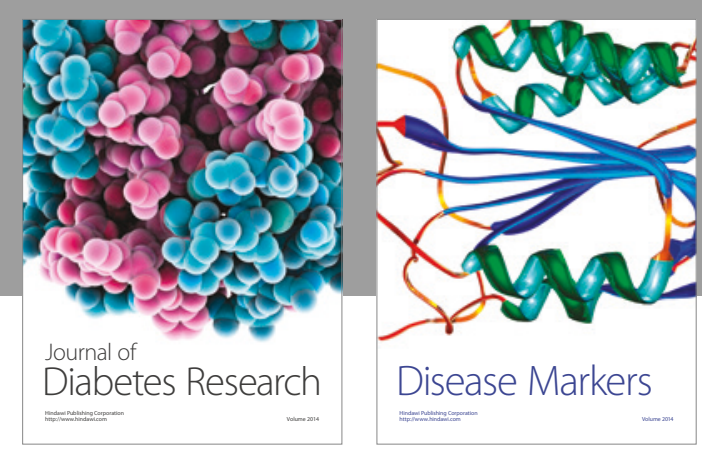

Disease Markers
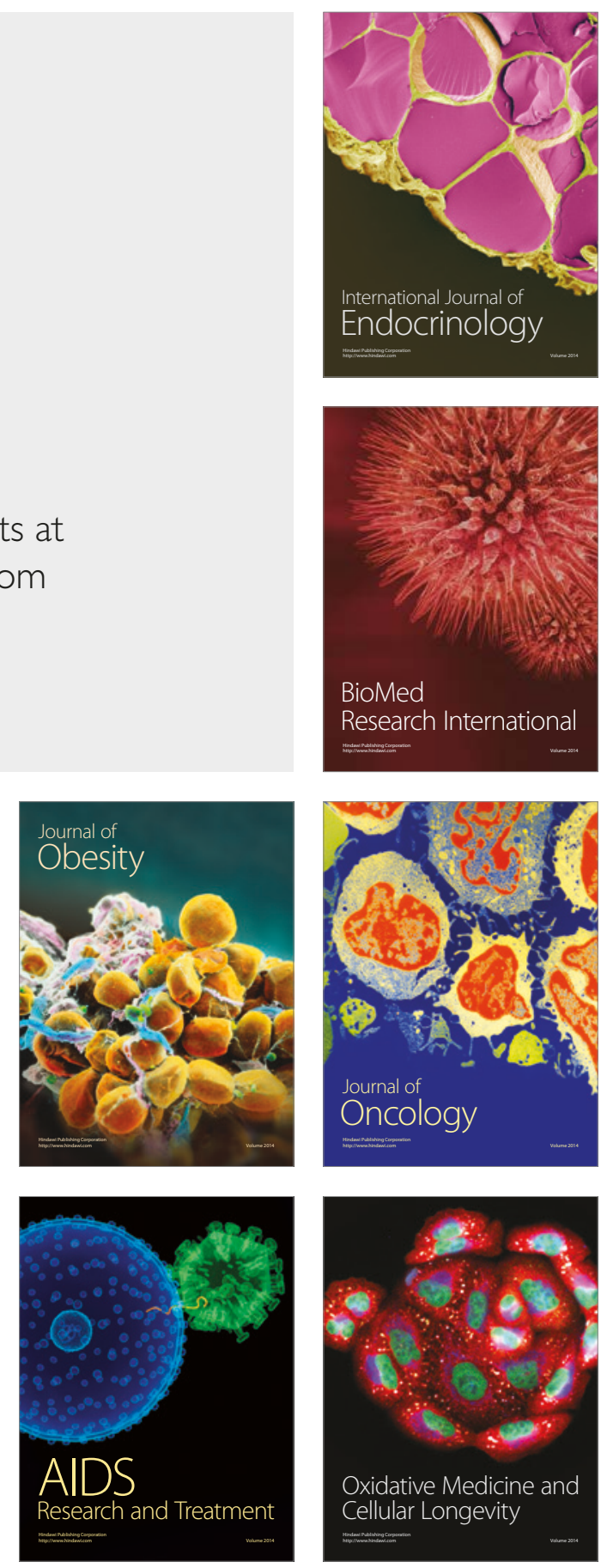